\title{
Hyposialylated IgG activates endothelial IgG receptor FcyRIIB to promote obesity-induced insulin resistance
}

\author{
Keiji Tanigaki, ${ }^{1}$ Anastasia Sacharidou, ${ }^{1} J u n$ Peng, ${ }^{1}$ Ken L. Chambliss, ${ }^{1}$ Ivan S. Yuhanna, ${ }^{1}$ Debabrata Ghosh, ${ }^{2,3}$ Mohamed Ahmed, ${ }^{1}$ \\ Alexander J. Szalai, ${ }^{4}$ Wanpen Vongpatanasin, ${ }^{5}$ Robert F. Mattrey, ${ }^{3}$ Qiushi Chen, ${ }^{6}$ Parastoo Azadi, ${ }^{6}$ Ildiko Lingvay, ${ }^{7}$ Marina Botto, ${ }^{8}$ \\ William L. Holland, ${ }^{9}$ Jennifer J. Kohler, ${ }^{10}$ Shashank R. Sirsi, ${ }^{2,3}$ Kenneth Hoyt, ${ }^{2,3}$ Philip W. Shaul, ${ }^{1}$ and Chieko Mineo ${ }^{1}$
}

\begin{abstract}
'Center for Pulmonary and Vascular Biology, Department of Pediatrics, University of Texas Southwestern Medical Center, Dallas, Texas, USA. ²Department of Bioengineering, University of Texas at Dallas, Richardson Texas, USA. ${ }^{3}$ Department of Radiology, University of Texas Southwestern Medical Center, Dallas, Texas, USA. "Division of Clinical Immunology and Rheumatology, Department of Medicine, University of Alabama at Birmingham, Birmingham, Alabama, USA. ${ }^{5}$ Hypertension Section, Division of Cardiology, Department of Internal Medicine, University of Texas Southwestern Medical Center, Dallas, Texas, USA. ${ }^{\circ}$ The Complex Carbohydrate Research Center, University of Georgia, Athens, Georgia, USA. 'Division of Endocrinology, Diabetes, and Metabolism and Department of Clinical Sciences, University of Texas Southwestern Medical Center, Dallas, Texas, USA. ${ }^{8}$ Centre for Complement and Inflammation Research, Division of Immunology and Inflammation, Department of Medicine, Imperial College London, London, United Kingdom. ${ }^{9}$ Touchstone Diabetes Center, Department of Internal Medicine, and ${ }^{10}$ Department of Biochemistry, University of Texas Southwestern Medical Center, Dallas, Texas, USA.

Type 2 diabetes mellitus (T2DM) is a common complication of obesity. Here, we have shown that activation of the IgC receptor Fc $\gamma$ RIIB in endothelium by hyposialylated IgG plays an important role in obesity-induced insulin resistance. Despite becoming obese on a high-fat diet (HFD), mice lacking FcyRIIB globally or selectively in endothelium were protected from insulin resistance as a result of the preservation of insulin delivery to skeletal muscle and resulting maintenance of muscle glucose disposal. IgG transfer in IgG-deficient mice implicated IgC as the pathogenetic ligand for endothelial Fc $\gamma$ RIIB in obesityinduced insulin resistance. Moreover, IgC transferred from patients with T2DM but not from metabolically healthy subjects caused insulin resistance in IgG-deficient mice via Fc $\gamma$ RIIB, indicating that similar processes may be operative in T2DM in humans. Mechanistically, the activation of FcyRIIB by IgC from obese mice impaired endothelial cell insulin transcytosis in culture and in vivo. These effects were attributed to hyposialylation of the Fc glycan, and IgC from T2DM patients was also hyposialylated. In HFD-fed mice, supplementation with the sialic acid precursor $\mathrm{N}$-acetyl-D-mannosamine restored IgC sialylation and preserved insulin sensitivity without affecting weight gain. Thus, IgC sialylation and endothelial FcyRIIB may represent promising therapeutic targets to sever the link between obesity and T2DM.
\end{abstract}

\section{Introduction}

Diabetes is a major cause of morbidity and mortality and high health care costs worldwide $(1,2)$. There has been an alarming rise in the incidence of diabetes, with the number of adult diabetics globally rocketing from 108 million in 1980 to 422 million in 2014 (3), and the bulk of the increase involves obesity-induced insulin resistance and type 2 diabetes mellitus (T2DM) (4). Despite the recognition that weight control measures are critically important to T2DM prevention and management, long-term results from lifestyle-directed or pharmacologic interventions are generally disappointing $(5,6)$. Although our understanding of the mechanisms by which obesity causes insulin resistance and T2DM has been improving (7), novel insights and therapeutic approaches are urgently needed to combat the T2DM that so commonly complicates obesity.

A major aspect of obesity-induced insulin resistance is impaired insulin action in the skeletal muscle, where up to $80 \%$ of whole-body glucose disposal normally occurs $(8,9)$. In mice,

Authorship note: P.W. Shaul and C. Mineo are co-senior authors. Conflict of interest: The authors have declared that no conflict of interest exists. Submitted: June 30, 2016; Accepted: October 17, 2017.

Reference information: J Clin Invest. 2018;128(1):309-322.

https://doi.org/10.1172/JCl89333. diet-induced obesity causes a marked blunting of skeletal muscle glucose disposal that occurs primarily because of a diminution in skeletal muscle insulin delivery (10). Insulin delivery and participation in skeletal muscle glucose metabolism are intricately influenced by processes occurring in the muscle microvasculature (10). Via its actions in the endothelium, insulin promotes capillary recruitment and increases blood flow in skeletal muscle, and the ultimate delivery of insulin from the circulation to the myocyte requires endothelial transcytosis of the hormone (11). These collective processes promote skeletal muscle glucose disposal. Potential clues regarding pathologic processes in skeletal muscle endothelium that may underlie insulin resistance arose from our recent studies of the pentraxin C-reactive protein (CRP). The studies were prompted by clinical reports of an association between T2DM and modest elevations in CRP, which occur in the setting of obesity and other chronic inflammatory conditions (12-14). Using a CRP transgenic mouse, we showed that an elevation in CRP causes insulin resistance and that this is mediated by Fc $\gamma$ RIIB (15), which is an inhibitory receptor for IgG that also governs cellular responses to CRP and the related mouse pentraxin serum amyloid P (SAP) component (16-18). We further revealed that Fc $\gamma$ RIIB is expressed in both human and mouse endothelium, particularly in skeletal muscle microvascular endothelium; that an elevation in CRP attenuates insulin delivery to skeletal muscle in 

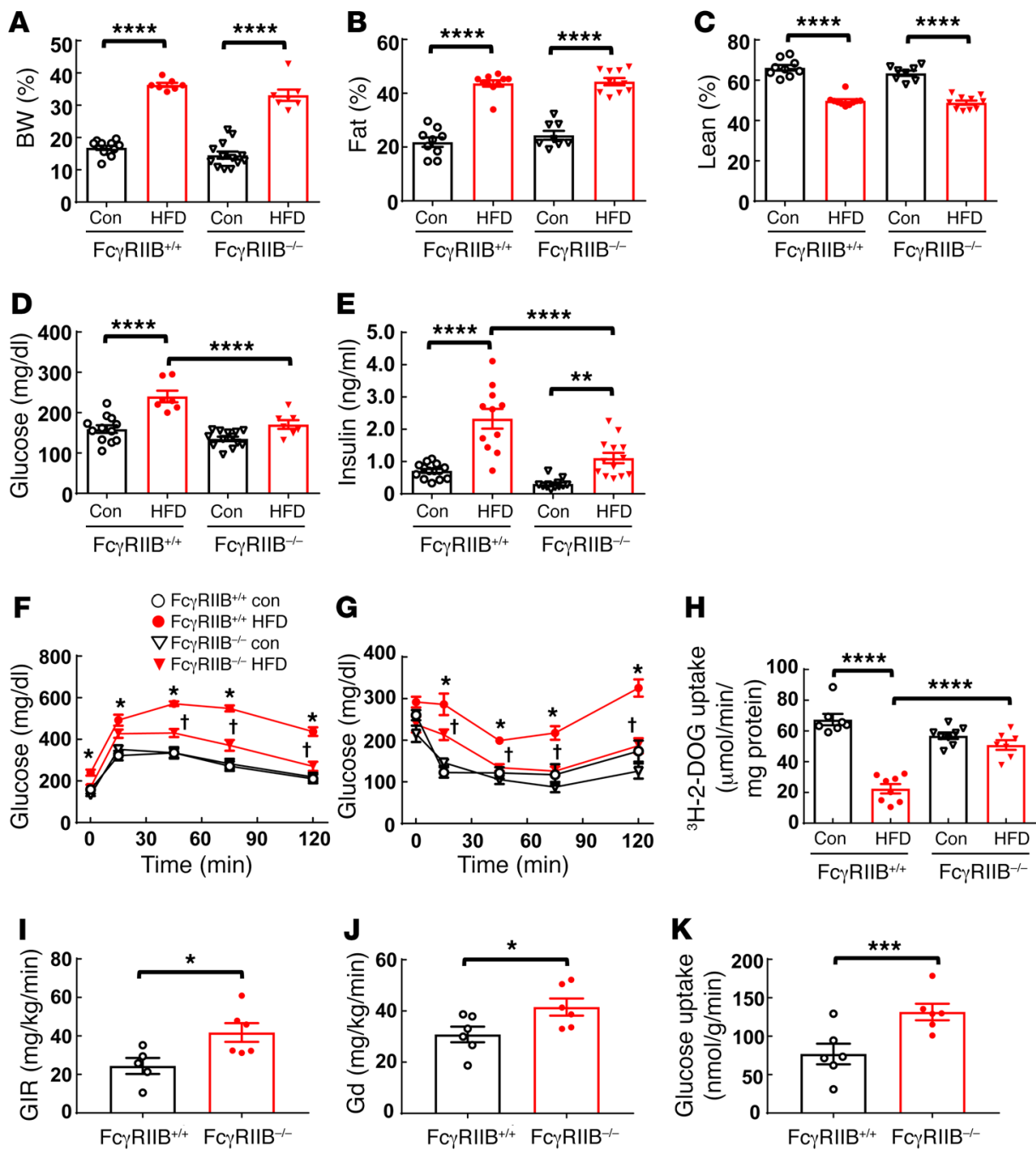

Figure 1. FcyRIIB-/- mice are protected from obesity-induced glucose intolerance and insulin resistance. Beginning at 5 weeks of age, male $\mathrm{Fc} \gamma \mathrm{RIIB}^{+/+}$and $\mathrm{Fc} \gamma-$ $\mathrm{RIIB}^{-1-}$ mice were fed a control diet (Con) or a HFD for 12 weeks, and BW (A) and fat and lean mass ( $\mathbf{B}$ and $\mathbf{C}$ ) were evaluated. Fasting blood glucose (D) and insulin (E) levels were measured ( $n=7-13)$, and a CTT (F) was performed. Following a 1-week recovery while continuing the assigned diets, the mice were fasted, and an ITT (G) was performed. (F and $\mathbf{G}) n=6-13$. ${ }^{*} P$ $<0.05$ versus $\mathrm{F} c \gamma \mathrm{RIIB}^{+/+}$control; ${ }^{\dagger} P<0.05$ versus $\mathrm{Fc} \gamma \mathrm{RIIB} \mathrm{B}^{+/+} \mathrm{HFD}$. (H) Following another week of recovery, the mice were fasted, and $\left[{ }^{3} \mathrm{H}\right]$-2-deoxyglucose $\left({ }^{3} \mathrm{H}-2-\mathrm{DOC}\right)$ uptake in skeletal muscle was measured. $n=7-8$. (I-K) Euglycemic-insulinemic clamps were performed on mice on a HFD, and the GIR (I), peripheral $\mathrm{Gd}(\mathrm{J})$, and skeletal glucose uptake (K) were evaluated. $n=5-6$. Values represent the mean \pm SEM. ${ }^{*} P<0.05,{ }^{* *} P<0.01,{ }^{* * *} P<0.005$, and ${ }^{* * *} P<0.001$, by 1 -way ANOVA with Tukey's post-hoc test (A-E and $\mathbf{H})$, 2-way ANOVA with Tukey's post-hoc test ( $\mathbf{F}$ and G), and Student's $t$ test (I-K). vivo and the transendothelial transport of insulin in cell culture; and that the activation of Fc $\gamma$ RIIB in endothelium in response to an increase in CRP disrupts skeletal muscle glucose disposal and thereby invokes insulin resistance $(15,18,19)$. The perturbations in glucose homeostasis observed in mice when CRP is artificially elevated to increase the abundance of an Fc $\gamma$ RIIB ligand phenocopy many of the features of obesity-induced insulin resistance (10). However, whether Fc $\gamma$ RIIB or any of its ligands participate in obesity-induced insulin resistance is unknown.

Prompted by the need to better understand the pathogenesis of obesity-related glucose dysregulation, we sought to determine the potential role of $\mathrm{Fc}$ receptors in obesity-induced insulin resistance. We designed experiments in mice and in cell culture to test the hypothesis that Fc $\gamma$ RIIB mediates obesity-induced insulin resistance. We also performed studies to address the following additional questions: (a) If Fc $\gamma$ RIIB is required, in what cell type does the receptor participate in obesity-induced insulin resistance? (b) What is the ligand for FcyRIIB in its mediation of obesity-induced insulin resistance? (c) How is the ligand altered during obesity? (d) Is there any evidence that processes revealed in obese mice may translate to humans with T2DM? (e) Can the diabetogenic Fc $\gamma$ RIIB ligand be manipulated during the development of obesity to prevent insulin resistance?

\section{Results}

Role of Fc $\gamma$ RIIB. To first determine whether Fc $\gamma$ RIIB participates in obesity-induced insulin resistance, WT $\left(\mathrm{Fc}_{\mathrm{RIIB}} \mathrm{B}^{++}\right)$ and $\mathrm{Fc}_{\mathrm{RIIB}}{ }^{-/-}$mice were fed a control chow diet or a high-fat diet (HFD) for 12 weeks, and body composition and glucose homeostasis were evaluated. The 2 genotype groups displayed comparable increases in BW and fat mass and correspondingly similar declines in lean body mass on the HFD (Figure 1, A-C). In addition, we observed no differences between $\mathrm{Fc}_{\mathrm{RIIB}}{ }^{+/+}$ and $\mathrm{Fc}_{\mathrm{RIIB}}{ }^{-/-}$mice in the alterations of food consumption or energy expenditure that occurred with HFD-induced obesity (Supplemental Figure 1, A-E; supplemental material available online with this article; https://doi.org/10.1172/JCI89333DS1). Circulating levels of triglycerides and free fatty acids were also similar in HFD-fed Fc $\gamma \mathrm{RIIB}^{+/+}$and Fc $\gamma \mathrm{RIIB}^{-/-}$mice (Supplemental Figure 2, A and B). Whereas $\mathrm{Fc}_{\mathrm{R}} \mathrm{RIB}^{+/+}$mice had elevated fasting plasma glucose and insulin levels following HFD consumption, $\mathrm{Fc}_{\mathrm{RIIB}}{ }^{-/-}$mice were protected from fasting hyperglycemia and had less fasting hyperinsulinemia than $\operatorname{did~} \mathrm{Fc} \gamma \mathrm{RIIB}^{+/+}$ mice (Figure 1, D and E). In the Fc $\gamma \mathrm{RIIB}^{+/+}$mice fed a HFD, glucose tolerance tests (GTTs) and insulin tolerance tests (ITTs) were predictably abnormal compared with those for chow-fed 

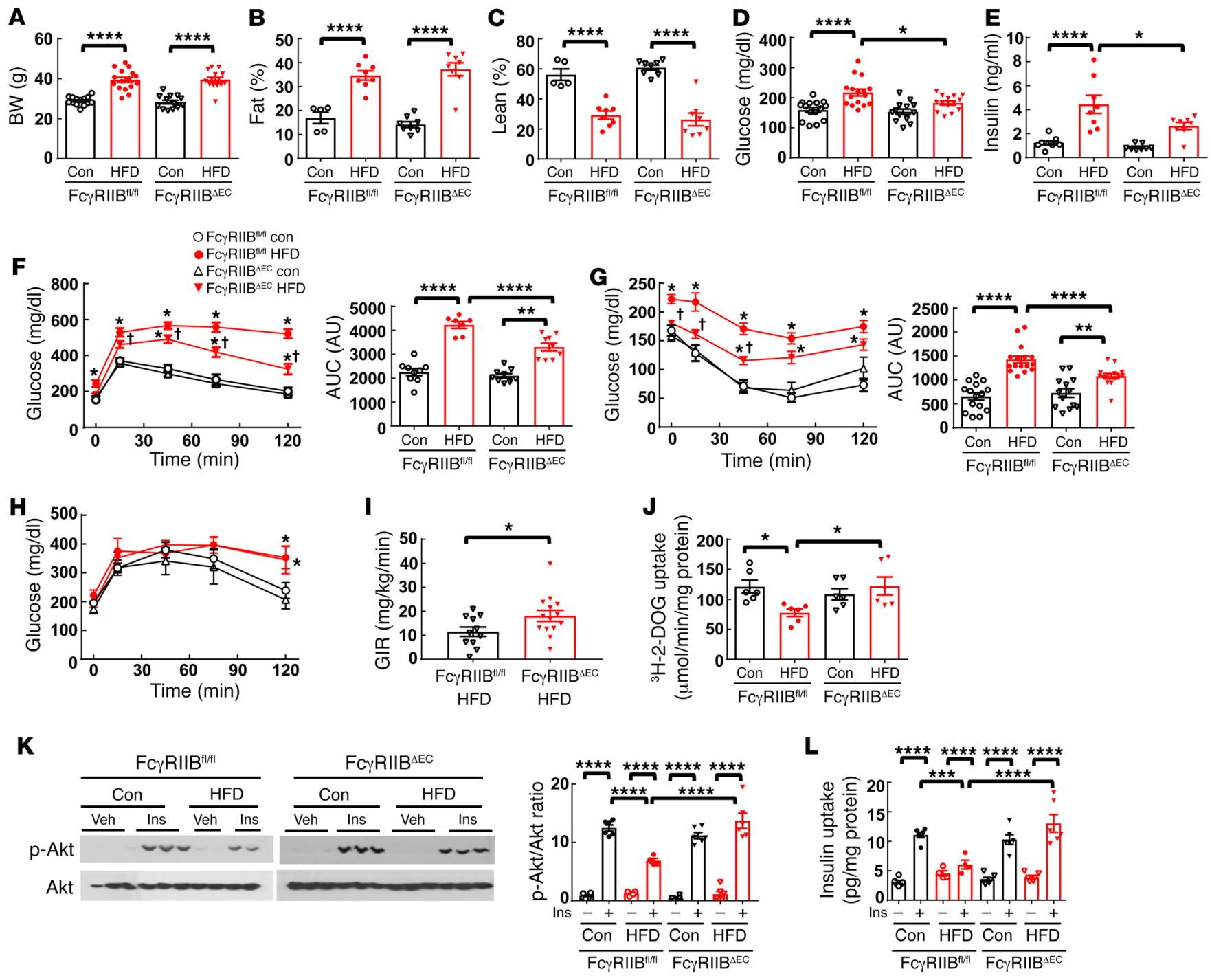

Figure 2. Mice with endothelium-specific deletion of $F c \gamma R I I B\left(F c \gamma R I I B^{\Lambda E C}\right)$ are protected from obesity-induced glucose intolerance and insulin resistance due to the preservation of skeletal muscle insulin delivery, insulin action, and glucose uptake. (A-C) Male Fc $\gamma R \| B^{f l / f l}$ and $F c \gamma R I I B B^{\triangle E C C}$ mice were fed a control diet or a HFD for 12 weeks, and BW $(\mathbf{A})$ and fat and lean mass (B and $\mathbf{C})$ were evaluated. $n=5-13(\mathbf{A}-\mathbf{C})$. Fasting blood glucose (D) and insulin (E) levels were measured ( $n=8-16)$, and a GTT (F; right panel shows the AUC) was performed. An ITT (G; right panel shows the AUC) and a PTT (H) were then performed, each following a 1-week recovery while mice continued the assigned diets. (F-H) $n=6-13$. (I) In separate mice, following 12 weeks on a HFD, a hyperinsulinemic-euglycemic clamp was performed, and the GIR was calculated. $n=11-14$. (J) One week after the PTT, the mice in $\mathbf{A}-\mathbf{H}$ were fasted, and $\left[{ }^{3} \mathrm{H}\right]$-2-deoxyglucose uptake in skeletal muscle was measured. $n=7-8$. $(\mathbf{F}-\mathbf{H}){ }^{*} P<0.05$ versus $\mathrm{Fc} \gamma \mathrm{RIIB} \mathrm{B}^{+/+}$control diet; $\nmid P<0.05$ versus Fc $\gamma \mathrm{RIIB}+/+\mathrm{HFD}$. (K and L) Following 12 weeks on a control diet or a HFD, mice were fasted and i.v. injected with PBS (Veh) or insulin (Ins) (1 unit/kg BW), and 5 minutes later, skeletal muscle was harvested, the phosphorylation of Akt (Ser473) was assessed by immunoblotting (K), and muscle insulin content was measured by ELISA (L). (K and $\mathbf{L}) n=4-6$. Values represent the mean \pm SEM. ${ }^{*} P<0.05,{ }^{* *} P<0.01,{ }^{* * *} P<0.005$, and ${ }^{* * * *} P<0.001$, by 1 -way ANOVA with Tukey's posthoc test (A-E, and $\mathbf{I}-\mathbf{L}), 2$-way ANOVA with Tukey's post-hoc test $(\mathbf{F}-\mathbf{H})$, and Student's $t$ test (I).

WT mice (Figure 1, F and G). In contrast, Fc $\gamma \mathrm{RIIB}^{-/-}$mice were protected from HFD-induced glucose intolerance and insulin resistance. Since classical functions of Fc $\gamma$ RIIB often entail partnership with one of the activating Fc receptors - Fc $\gamma$ RI, Fc $\gamma$ RIII, or Fc $\gamma$ RIV (20) - we also sought to determine how activating Fc receptor disruption by deletion of the shared $\gamma$ chain impacts obesity-induced insulin resistance. $\mathrm{Fc} \gamma^{+/+}$and $\mathrm{Fc} \gamma^{-/}$mice on a HFD developed comparable obesity and comparable glucose intolerance and insulin resistance (Supplemental Figure 3, $A-G$ ), indicating that activating $F c$ receptors do not participate in obesity-related glucose dysregulation.
We then determined the basis for the protection from obesityinduced insulin resistance with FcyRIIB deletion. Noting that Fc $\gamma$ RIIB activation by an artificial elevation in CRP blunts muscle glucose disposal (15), we next evaluated skeletal muscle glucose uptake in $\mathrm{Fc}_{\mathrm{RIIB}}{ }^{+/+}$and $\mathrm{Fc} \gamma \mathrm{RIIB}^{-/-}$mice on the 2 diets. Consumption of the HFD and the resulting obesity led to predictably attenuated glucose uptake in the skeletal muscle of $\mathrm{Fc}_{\mathrm{R}} \mathrm{RIIB}^{+/+}$ mice. However, despite comparable obesity development, we found that muscle glucose disposal was fully preserved in the Fc $\mathrm{RIIB}^{-/-}$mice (Figure 1H). Euglycemic-hyperinsulinemic clamp experiments further showed that, compared with $\mathrm{Fc} \gamma \mathrm{RIIB}^{+/+}$mice, 

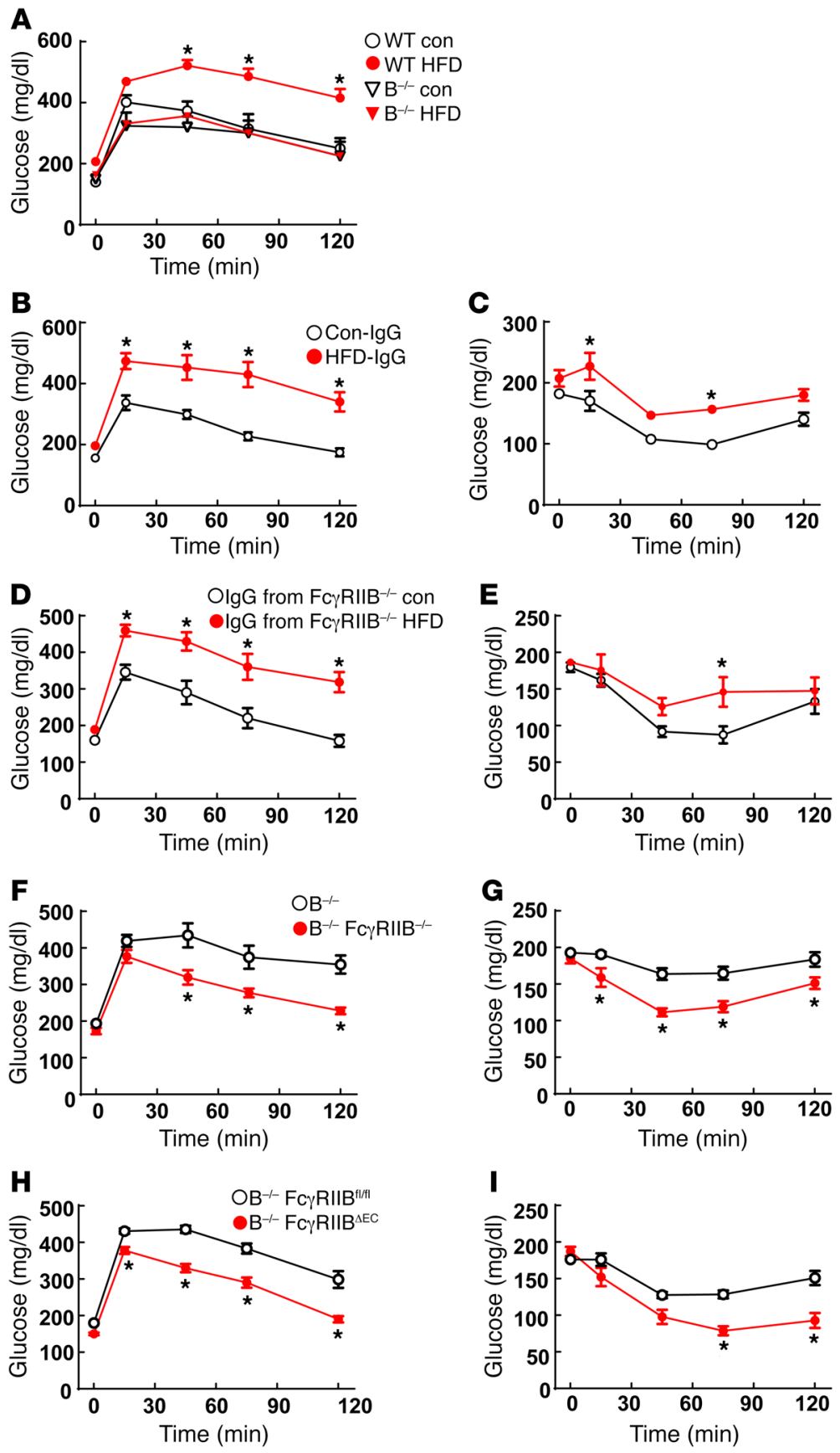

Figure 3. IgG isolated from HFD-fed WT mice induces glucose intolerance and insulin resistance in $\mathrm{B}^{-/-}$mice via endothelial Fc $\gamma$ RIIB. (A) Male WT or $\mathrm{B}^{-/-}$mice were fed a control diet or a HFD for 12 weeks, and a CTT was performed. $n=7-9$. ${ }^{*} P<0.05$ versus WT control. (B and $\mathbf{C}$ ) Male $\mathrm{B}^{-/-}$mice were fed a HFD for 12 weeks, and while continuing the HFD, they were i.p. injected with IgG $(150 \mu \mathrm{g} /$ mouse, 2 times/ week) isolated from WT mice fed either a control diet (ConIgG) or a HFD (HFD-IgG). GTTs (B) and ITTs (C) were performed after 1 week and 2 weeks of IgG administration, respectively. (B and $\mathbf{C}) n=6-7 .{ }^{*} P<0.05$ versus Con-IgG. ( $\mathbf{D}$ and $\mathbf{E}$ ) Using the study design and readouts described for $\mathbf{B}$ and $\mathbf{C}$, IgG transfer experiments were performed in male $\mathrm{B}^{-/-}$mice given IgC isolated from $\mathrm{Fc}_{\mathrm{CR}} \mathrm{RIB}^{-1-}$ mice fed either a control diet or a HFD. Endpoints were the GTT (D) and ITT (E). (D and E) $n=$ 6-7. ${ }^{*} P<0.05$ versus IgG from Fc $\gamma \mathrm{RIIB}^{-/-}$control mice. ( $\mathbf{F}$ and G) IgC transfer studies were performed in male $\mathrm{B}^{-/-}$versus $\mathrm{B}^{-/-}$ $\mathrm{Fc}_{\mathrm{RRIIB}}{ }^{-/}$mice administered IgG isolated from HFD-fed WT mice. GTTs (F) and ITTs (G) were performed. $(\mathbf{F}$ and $\mathbf{G}) n=7-8$. ${ }^{*} P<0.05$ versus $B^{-/-}$mice. (H and $\mathbf{I}$ ) IgG transfer experiments were performed in male $\mathrm{B}^{-/-} \mathrm{Fc} \gamma \mathrm{R} / I \mathrm{~B}^{\mathrm{fl} / \mathrm{fl}}$ and $\mathrm{B}^{-/-} \mathrm{Fc} \gamma \mathrm{RIIB}{ }^{\Delta \mathrm{EC}}$ mice administered IgC isolated from HFD-fed WT mice. GTTs (H) and ITTs (I) were performed. (H and I) $n=11-14 .{ }^{*} P<0.05$ versus $\mathrm{B}^{-/-} \mathrm{Fc} \gamma \mathrm{R} / \mathrm{B} \mathrm{B}^{\mathrm{fl} / \mathrm{fl}}$ mice. Values represent the mean $\pm \mathrm{SEM}$. $P$ values were determined by 2-way ANOVA with Tukey's post-hoc test.

surprising discovery when one considers that Fc $\gamma$ RIIB classically tempers immune responses (20) and that numerous pathogenetic processes in obesity are proinflammatory in nature (21).

Role of endothelial $F c \gamma$ RIIB. We next studied the role of endothelial Fc $\gamma$ RIIB in obesity-induced glucose dysregulation. This was accomplished using mice generated by crossing floxed Fc $\gamma$ RIIB mice $\left(F_{c} \gamma R\right.$ RIIB $\left.^{\mathrm{H} / \mathrm{l} I}\right)$ (19) with vascular endothelial cadherin promoter-driven Cre (VECad-Cre) mice (22). The resulting Fc $\gamma \mathrm{RIIB}^{\mathrm{n} / \mathrm{l}}$ VECad-Cre mice lacking the receptor in endothelium are designated herein as Fc $\gamma$ RIIB ${ }^{\triangle E C}$ mice. Compared with control diet-fed mice, upon HFD feeding, $\mathrm{F}_{\mathrm{C}} \gamma \mathrm{RIB}^{\mathrm{f} / \mathrm{fl}}$ and $\mathrm{Fc} \gamma \mathrm{RIIB}{ }^{\mathrm{AEC}}$ mice showed similar BW gains and fat mass expansion (Figure 2, $\mathrm{A}-\mathrm{C}$ ). There were also no genotype-related differences in plasma levels of triglycerides or free fatty acids (Supplemental Figure 6, A and B). However, despite equal degrees of adiposity, relative to $\mathrm{Fc}_{\mathrm{RIIB}} \mathrm{R}^{\mathrm{f} / \mathrm{I}}$ controls, Fc $\gamma$ RIIB $^{\triangle \mathrm{EC}}$ mice showed protection against

HFD-fed Fc $\gamma \mathrm{RIIB}^{-/-}$mice had an increased glucose infusion rate (GIR) and a greater glucose disposal (Gd) rate (Figure 1, I and J). In addition, we confirmed the increase in skeletal muscle glucose uptake observed with Fc $\gamma$ RIIB deletion, despite diet-induced obesity (Figure 1K). There were no differences between HFD-fed Fc $\gamma$ $\mathrm{RIIB}^{+/+}$and $\mathrm{Fc}_{\mathrm{RIIB}}{ }^{-/}$mice in terms of serum insulin changes in response to glucose (Supplemental Figure 4), nor were changes detected in basal hepatic glucose production or hepatic insulin sensitivity (Supplemental Figure 5). Collectively, these findings indicate that, independent of effects on adiposity and independent of activating Fc receptors, Fc $\gamma$ RIIB plays an important role in obesity-induced insulin resistance by mediating the obesityinduced decline in skeletal muscle glucose disposal. This is a
HFD-induced fasting hyperglycemia and hyperinsulinemia (Figure 2, D and $\mathrm{E}$ ). $\mathrm{Fc} \gamma \mathrm{RIIB}^{\mathrm{EEC}}$ mice were also partially protected from abnormal HFD-induced GTTs and ITTs (Figure 2, F and G), with AUC calculations indicating $40 \%-54 \%$ protection. A $58 \%$ increase in the GIR during euglycemic hyperinsulinemic clamps (Figure 2I) provided additional evidence of an improvement in overall insulin sensitivity, despite diet-induced obesity with selective endothelial Fc $\gamma$ RIIB silencing. Pyruvate tolerance tests (PTTs) performed to evaluate hepatic insulin sensitivity revealed that endothelial cell FcrRIIB deletion affords no protection from obesity-induced hepatic insulin resistance (Figure $2 \mathrm{H}$ ). The improvement in overall insulin sensitivity in HFD-fed Fc $\gamma$ RIIB $^{\triangle E C}$ mice was instead related to a normalization of skeletal muscle glucose uptake (Figure 2J). 

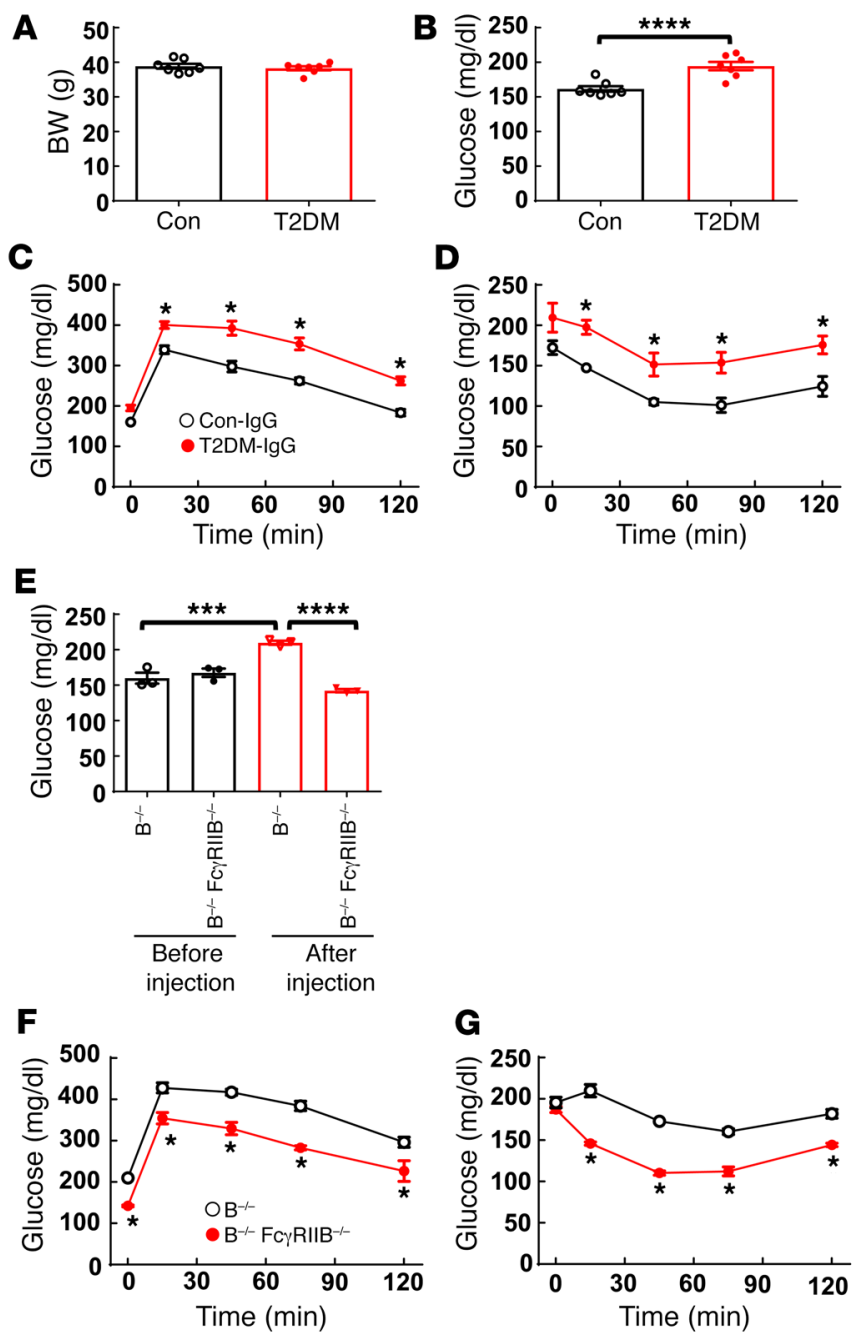

Next, to determine how endothelial FcyRIIB influences insulin action in the skeletal muscle, we evaluated Akt phosphorylation in muscle harvested 5 minutes after i.v. insulin injection (19) (Figure $2 \mathrm{~K})$. Insulin predictably caused a marked increase in Akt (Ser473) phosphorylation in muscle in $\mathrm{Fc}_{\mathrm{RIIB}} \mathrm{B}^{\mathrm{A} / \mathrm{l}}$ mice fed the control diet, and the response was attenuated in Fc $\gamma \mathrm{RIIB}^{\mathrm{A} / \mathrm{l}}$ mice following HFD feeding. In contrast, in Fc $\gamma \mathrm{RIIB}^{\triangle \mathrm{EC} C}$ mice, we observed a preservation of insulin activation of skeletal muscle Akt, despite HFD intake and obesity. We then sought to determine how endothelial Fc $\gamma$ RIIB impacts skeletal muscle responses to circulating insulin in the setting of obesity. Whereas a $257 \%$ increase in skeletal muscle insulin content was observed 5 minutes after insulin injection in the Fc $\gamma \mathrm{RIIB}^{\mathrm{f} / \mathrm{II}}$ mice fed a control chow diet, there was only a $32 \%$ increase in muscle insulin content in Fc $\gamma$ RIIB ${ }^{\mathrm{A} / \mathrm{l}}$ mice with diet-induced obesity (Figure 2L). In contrast, lean and obese Fc $\gamma \mathrm{RIIB}^{\triangle \mathrm{EC}}$ mice showed comparable $188 \%$ and $231 \%$ increases in insulin uptake in the skeletal muscle following insulin administration. These cumulative findings demonstrate that endothelial Fc $\gamma$ RIIB is responsible for the decrease in skeletal muscle insulin delivery that occurs in obesity and results in impaired muscle glucose disposal and insulin resistance.

Identifying IgG as the operative FcyRIIB ligand. Having determined that there is an important role for FcyRIIB in obesityinduced insulin resistance, we next sought to identify the opera-
Figure 4. IgC isolated from human T2DM patients induces glucose intolerance and insulin resistance in $\mathrm{B}^{-/-}$mice via FcyRIIB. (A-D) Male $\mathrm{B}^{-/-}$mice were fed a HFD for 12 weeks, and while continuing the HFD, they were i.p. injected with IgG ( $150 \mu \mathrm{g} /$ mouse, 2 times/week) isolated from non-T2DM control subjects versus IgG from T2DM subjects. After 1 week of injections, (A) BW was measured, (B) plasma glucose was measured after a 4- to 6-hour fast, and (C) a GTT was performed. (D) An ITT was performed following a second week of IgG injections. (A-D) $n=6$ IgG samples, each evaluated in 3 to 5 mice. (C and $\mathbf{D}$ ) ${ }^{*} P<0.05$ versus Con-IgG. (E-C) Using the study design described for $\mathbf{A}-\mathbf{D}$, lgG transfer experiments were performed by administering human T2DM-IgG to male $\mathrm{B}^{-/-}$mice and $\mathrm{B}^{-/-} \mathrm{Fc}_{\mathrm{R}} \mathrm{RIIB} \mathrm{B}^{-/-}$ mice. (E) Fasting plasma glucose levels were measured before IgG injection and at 1 week. $n=3$ IgG samples. (F) A GTT was performed after 1 week of injections, and (G) an ITT was performed after 2 weeks of injections. (F and G) $n=3$ IgG samples. ${ }^{*} P<0.05$ versus $B^{-/-}$. Values represent the mean \pm SEM. ${ }^{*} P<0.05,{ }^{* * *} P<0.005,{ }^{* * *} P<0.001$, by Student's $t$ test (A and $\mathbf{B}$, with significance found in B), 1-way ANOVA with Tukey's post-hoc test (E), and 2-way ANOVA with Tukey's post-hoc test (C, D, F, and $\mathbf{G}$ ).

tive receptor ligand. The 3 known ligands, IgG, CRP, and SAP, bind to identical amino acids in the extracellular domain of $\mathrm{Fc}$ receptors (17). Consistent with previous reports $(23,24)$, we found that neither plasma CRP nor SAP was elevated by diet-induced obesity in mice (Supplemental Figure 7, A and B). However, since SAP is the acute-phase reactant pentraxin in mice and CRP is not $(25,26)$, and, as such, SAP abundance may change earlier during the genesis of obesity, we compared the development of obesity-induced insulin resistance in $\mathrm{SAP}^{+/+}$with that of $\mathrm{SAP}^{-/-}$mice. After 12 weeks of HFD feeding, mice in both genotype groups had similar weight gains and adiposity (Supplemental Figure 7, C-E), developed comparable fasting hyperglycemia and hyperinsulinemia (Supplemental Figure 7, F and G), and had similarly affected GTTs and ITTs (Supplemental Figure 7, H and I). Thus, the murine acute-phase reactant SAP did not participate in the pathogenesis of obesityinduced insulin resistance in the mouse model.

With CRP and SAP unlikely to be the operative Fc $\gamma R$ RIB ligand in obesity-induced insulin resistance in mice, we investigated the role of IgG in studies of Ig $\mu$ heavy-chain-null mice deficient in mature $\mathrm{B}$ cells and $\mathrm{IgG}$ production (designated herein as $\mathrm{B}^{-/}$mice). As with previously reported findings (27), in contrast to WT controls, $\mathrm{B}^{-/}$mice administered a HFD for 12 weeks did not develop glucose intolerance (Figure 3A). In IgG transfer experiments involving HFD-fed $\mathrm{B}^{-/}$recipients, IgG from WT mice fed a HFD (HFD$\operatorname{IgG}$ ) induced glucose intolerance and insulin resistance, whereas IgG from WT mice fed a control diet (Con-IgG) did not (Figure 3 , B and C). Of note, HFD-IgG transfer to a lean $\mathrm{B}^{-/-}$mouse does not cause insulin resistance (27), indicating that obesity-related changes in IgG are necessary but not sufficient for the development of insulin resistance. Circulating levels of total IgG (Supplemental Figure $8 \mathrm{~A}$ ) and of the 4 individual mouse IgG subclasses IgG1, IgG2b, IgG2c, and IgG3 (Supplemental Figure 8, B-E) were similar in the control diet- versus HFD-fed mice. As such, changes in the actions of IgGs, and not in their abundance, probably underlie their participation in obesity-related insulin resistance.

Since Fc $\gamma$ RIIB is expressed in B cells and modulates IgG production (20), the protection from obesity-induced insulin resistance seen in mice globally deficient in Fc $\gamma$ RIIB (Figure 1) may involve effects of receptor loss on IgG generation. This possibility was tested in $\operatorname{Ig} G$ transfer experiments using $\operatorname{Ig} G$ from control 
A
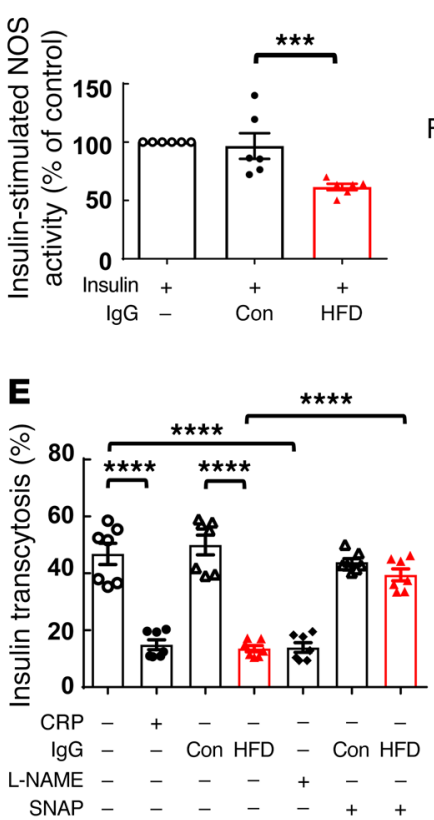

B

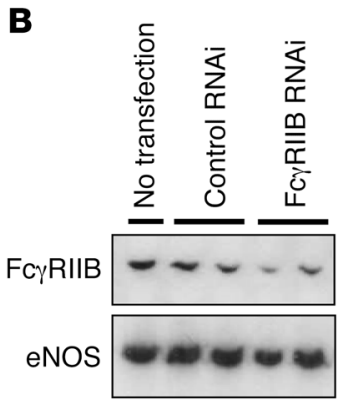

C

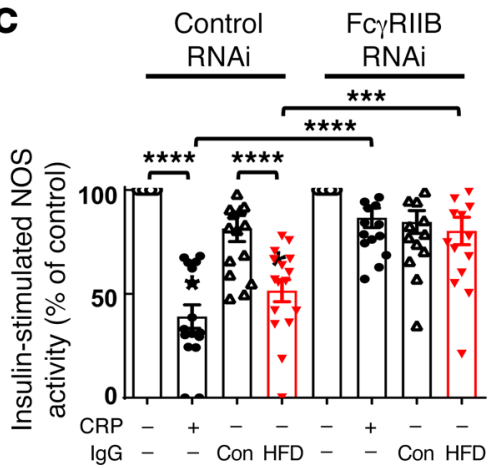

G

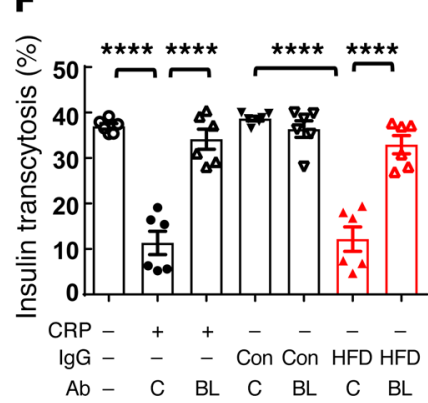

D
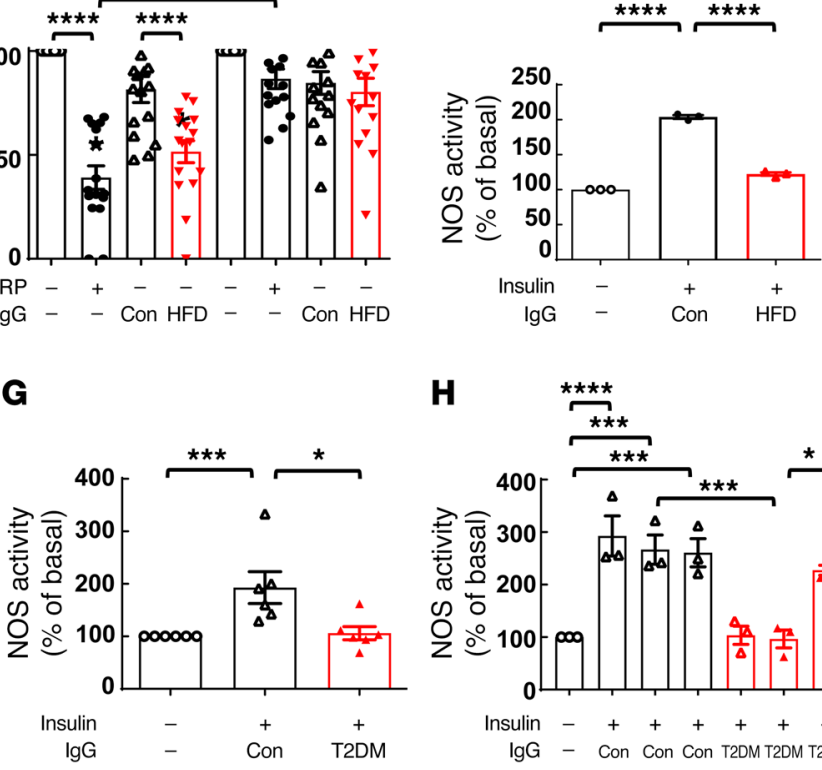

H

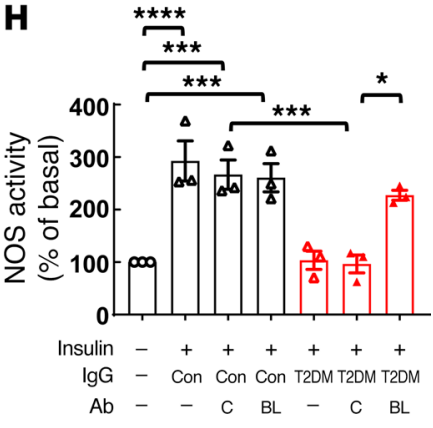

Figure 5. IgG from HFD-fed mice attenuates insulin-induced eNOS activation and transendothelial transport of insulin via FcyRIIB and eNOS antagonism, and IgG from T2DM subjects blunts insulin action in human endothelium via FcyRIIB. (A) BAECs were preincubated for 30 minutes with IgC isolated from control diet-fed (Con-lgG) or HFD-fed (HFD-IgG, $10 \mu \mathrm{g} / \mathrm{ml}$ ) mice, and eNOS activity stimulated by insulin (100 nM) was measured. $n=6$. (B and C) BAECs were transfected with or without control RNAi or RNAi targeting Fc $\gamma$ RIIB. Downregulation of Fc $\gamma$ RIIB was assessed by immunoblotting (B) using anti-Fc $\gamma$ RIIB or anti-eNOS antibody to evaluate protein loading. (C) Forty-eight hours after transfection, cells were pretreated with CRP (25 $\mu \mathrm{g} / \mathrm{ml})$, ConIgG, or HFD-IgG $(10 \mu \mathrm{g} / \mathrm{ml})$ for thirty minutes, and eNOS activity stimulated by insulin was measured. $n=16$. (D) HAECs were preincubated with Con-lgG or HFD-IgG $(10 \mu \mathrm{g} / \mathrm{ml})$, and eNOS activity under basal conditions or with insulin treatment was measured. $n=3$. (E) Confluent HAEC monolayers on Transwells were preincubated for 30 minutes with CRP, Con-IgG, or HFD-IgG in the absence or presence of the NOS inhibitor L-NAME (2 mM) or the NO donor SNAP (100 nM). FITC-conjugated insulin (50 nM) was added to the upper chamber, and the amount of insulin transcytosed to the lower chamber was evaluated after 2 hours. $n=7$. (F) Using the study design and methods described for $\mathbf{E}$, endothelial cell insulin transcytosis was evaluated without versus with CRP, Con-lgG, or HFD-IgG treatment, in the presence of subtype-matched control antibody (C, $10 \mu \mathrm{g} / \mathrm{ml}$ ) or the FcyRIIB-blocking antibody AT10 (BL, 10 $\mu \mathrm{g} / \mathrm{ml}$ ). $n=6$. (C) Insulin-induced eNOS activation was evaluated in HAECs with or without treatment with IgG from nondiabetic individuals (Con) or T2DM patients. $n=6$. (H) Additional NOS activity assays were performed in the presence of the subtype-matched control antibody (C) or the Fc $\gamma$ RIIB-blocking antibody (BL). $n=3$. Values represent the mean \pm SEM. ${ }^{*} P<0.05$, ${ }^{* *} P<0.005$, and ${ }^{* * * *} P<0.001$, by 1-way ANOVA with Tukey's post-hoc test.

chow-fed versus HFD-fed Fc $\gamma \mathrm{RIIB}^{-/-}$mice. Mimicking the findings obtained with IgG from WT mice, in contrast to IgG from control chow-fed Fc $\gamma \mathrm{RIIB}^{-/-}$mice, IgG from HFD-fed Fc $\gamma \mathrm{RIIB}^{-/-}$mice caused glucose intolerance and insulin resistance (Figure 3, D and E). Thus, the role of Fc $\gamma$ RIIB in obesity-related insulin resistance does not involve its function in B cells; instead, it resides in a target cell of IgG action. This was further explored in an IgG transfer experiment comparing responses to IgG obtained from WT mice fed a HFD (HFD-IgG) administered to HFD-fed $\mathrm{B}^{-/}$mice versus responses by HFD-fed $\mathrm{B}^{-/-} \mathrm{Fc}_{\mathrm{RIIB}}{ }^{-/}$double-KO mice. Whereas HFD-IgG caused abnormal GTTs and ITTs when given to $\mathrm{B}^{-1-}$ mice, we observed normal glucose tolerance and insulin sensitivity after HFD-IgG transfer into $\mathrm{B}^{-/-} \mathrm{Fc}_{\mathrm{R}} \mathrm{RIB}^{-/-}$mice (Figure 3, $\mathrm{F}$ and $\mathrm{G})$. We further assessed the Fc $\gamma$ RIIB-expressing IgG target cell of relevance using HFD-fed $\mathrm{B}^{-/-} \mathrm{Fc} \gamma \mathrm{RIIB}^{\mathrm{A} / \mathrm{l}}$ mice versus HFD-fed $\mathrm{B}^{-/-} \mathrm{Fc} \gamma \mathrm{RIIB}^{\triangle \mathrm{EC}}$ mice as IgG recipients. Whereas HFD-IgG caused abnormal GTTs and ITTs when given to $\mathrm{B}^{-/-} \mathrm{F} \gamma \mathrm{RIIB}^{\mathrm{A} / \mathrm{fl}}$ mice, the $\mathrm{B}^{-/-} \mathrm{Fc} \mathrm{RIIB}^{\triangle \mathrm{EC}}$ recipients of HFD-IgG had normal glucose tolerance and insulin sensitivity (Figure 3, $\mathrm{H}$ and I). Paralleling the protection from obesity-induced insulin resistance observed in $\mathrm{F}_{\mathrm{C}} \mathrm{RIIB}^{\triangle \mathrm{EC} C}$ mice (Figure 2), these findings indicate that IgG is the operative Fc $\gamma$ RIIB ligand in the disorder and that the relevant $\operatorname{Ig} G$ target cell in which Fc $\gamma$ RIIB participates is the endothelial cell.

IgG and T2DM in humans. We next examined whether the IgG-Fc $\gamma$ RIIB tandem plays a potential role in T2DM in humans. We performed IgG transfer studies in HFD-fed $\mathrm{B}^{-/-}$mice given IgG isolated from insulin-sensitive/nondiabetic control human subjects $(n=6)$ versus IgG from human subjects with T2DM (T2DM-IgG) $(n=6)$ (Supplemental Table 1). Following receipt of the control versus T2DM human IgG, we found no difference in BW (Figure 4A). However, compared with mice given control IgG, mice that received T2DM-IgG developed relative fasting hyperglycemia and had abnormal GTTs and ITTs (Figure 4, B-D). A requirement for Fc $\gamma$ RIIB in T2DM-IgG-induced glucose intolerance and insulin resistance was then tested using HFD-fed $\mathrm{B}^{-/-}$ mice and $\mathrm{B}^{-/-} \mathrm{Fc}_{\mathrm{RIIB}}{ }^{-/-}$mice as recipients. Prior to receiving IgG, the mice in the 2 genotype groups had comparable fasting glucose levels (Figure 4E). However, after injections of T2DM-IgG, the $\mathrm{B}^{-/-}$ 
mice had hyperglycemia and abnormal GTTs and ITTs, whereas the $\mathrm{B}^{-/-} \mathrm{Fc}_{\mathrm{IIB}} \mathrm{II}^{-/}$mice did not (Figure 4, E-G). Thus, in contrast to IgG obtained from healthy human subjects, IgG isolated from T2DM subjects caused glucose intolerance and insulin resistance in mice, and Fc $\gamma$ RIIB was required for the effect.

IgG and FCyRIIB actions in endothelium. Next, to identify the actions of IgG that adversely affect glucose homeostatic mechanisms via Fc $\gamma$ RIIB in endothelium, we took advantage of the knowledge that in cultured endothelial cells, Fc $\gamma$ RIIB stimulation antagonizes insulin activation of endothelial NOS (eNOS) (28). We compared eNOS activation by insulin in cultured bovine aortic endothelial cells (BAECs) exposed to IgG isolated from control mice (Con-IgG) versus IgG isolated from mice who had received a HFD (HFD-IgG). Whereas Con-IgG had no effect, HFD-IgG inhibited insulin-induced eNOS activation (Figure 5A). To then determine whether Fc $\gamma$ RIIB is required, BAECs were transfected with control RNAi or RNAi targeting Fc $\gamma$ RIIB to downregulate receptor expression (Figure 5B), and IgG actions were compared with those of CRP, a positive control Fc $\gamma$ RIIB ligand known to inhibit eNOS (28). In cells with a normal complement of endogenous Fc $\gamma$ RIIB, CRP inhibited insulin-stimulated eNOS activation as expected, and HFD-IgG had a similar effect (Figure 5C). In contrast, neither CRP nor HFD-IgG blunted insulin activation of eNOS in endothelial cells deficient in Fc $\gamma$ RIIB.

Next, we determined whether HFD-IgG modulation of insulin action occurs in human endothelium in studies of primary human aortic endothelial cells (HAECs). Mirroring the findings in BAECs, whereas Con-IgG did not alter insulin activation of eNOS in HAECs, HFD-IgG attenuated the response to insulin (Figure 5D). Knowing that insulin signaling and NO regulate the transcytosis of insulin by endothelial cells that is requisite for insulin action in skeletal muscle (29), we then evaluated the possible effects of HFD-IgG on endothelial cell insulin transcytosis in HAECs (Figure $5 E$ ). CRP as a positive control (19) caused a decline in insulin transcytosis, Con-IgG had no effect, and HFD-IgG caused a reduction in transcytosis comparable to that observed with CRP. NOS antagonism with nitro-L-arginine methyl ester (L-NAME) had an effect similar to that of HFD-IgG, and the latter was reversed by the NO donor S-nitroso- $N$-acetyl-penicillamine (SNAP) (Figure $5 \mathrm{E}$ ) and also by a blocking antibody against human Fc $\gamma$ RIIB (AT10) (Figure $5 F)$. Evaluations of paracellular transport using FITC-dextran and measurements of transendothelial electrical resistance (TEER) (Supplemental Figure 9, A-D) indicated that monolayer integrity remained intact under all the conditions studied. Importantly, the marked Fc $\gamma$ RIIB-dependent diminution in endothelial insulin transcytosis observed with HFD-IgG treatment in culture parallels our discovery that the obesity-related loss of skeletal muscle insulin delivery in vivo is fully reversed by endothelial Fc $\gamma$ RIIB silencing (Figure 2L). Since muscle insulin delivery in vivo is influenced by both insulin-induced changes in muscle capillary recruitment and blood flow and processes governing insulin transcytosis across the endothelial monolayer (30), we examined how the receptor may impact muscle microvascular functional responses to insulin in the setting of diet-induced obesity in vivo. We accomplished this using dynamic contrast-enhanced ultrasound (DCEUS) imaging of the proximal hind limb adductor muscle group and signal time-intensity curve analysis to assess capillary blood vol- ume (CBV) and microvascular blood flow (MBF) at baseline and at the end of a 2-hour hyperinsulinemic-euglycemic clamp in HFDfed Fc $\gamma \mathrm{RIIB}^{+/+}$and Fc $\gamma \mathrm{RIIB}^{-/-}$mice. The GIR during the clamps was greater in $\mathrm{Fc}_{\mathrm{RIIB}}{ }^{-/}$mice (Supplemental Figure 10A), mirroring the findings in Figure 1I. In DCE-US, peak intensity (Ipk) reflects $\mathrm{CBV}$, the time to peak (Tpk) and wash-in rate (WIR) reflect MBF, and the AUC and wash-out rate (WOR) are affected by both CBV and MBF. The Ipk was similar in the 2 genotype groups at baseline, and there were similar increases in responses to insulin (Supplemental Figure 10B). Tpk and WIR reflecting MBF were similar at baseline in $\mathrm{Fc}_{\mathrm{RIIB}}^{+/+}$and $\mathrm{Fc}_{\mathrm{RIIB}}{ }^{-/}$mice, and they did not change in response to insulin (Supplemental Figure 10, C and D). The AUC and WOR, which are affected by both CBV and MBF, were comparable in the 2 genotype groups at $t 0$, and they rose equivalently with insulin infusion (Supplemental Figure 10, E and F). As such, insulin induced an increase in CBV but did not affect $\mathrm{MBF}$ in obese $\mathrm{Fc} \gamma \mathrm{RIIB}^{+/+}$or $\mathrm{Fc} \gamma \mathrm{RIIB}^{-/-}$mice, and the responses were similar in the 2 genotype groups. Our observations of skeletal muscle insulin delivery in vivo (Figure $2 \mathrm{~L}$ ) and insulin transcytosis in cultured endothelial cells (Figure 5, E and F) indicate that the impairment in skeletal muscle insulin delivery that underlies obesity-related peripheral insulin resistance is primarily due to a diminution in endothelial insulin transcytosis caused by the IgG-endothelial Fc $\gamma$ RIIB tandem.

Seeking evidence of a possible adverse effect of human T2DM IgG on insulin action in human endothelium of relevance to glucose homeostasis, we next evaluated insulininduced eNOS activation in HAECs in the presence of IgG from insulin-sensitive individuals or subjects with T2DM. Similar to mouse HFD-IgG (Figure 5D), T2DM-IgG inhibited eNOS activation by insulin (Figure $5 \mathrm{G}$ ), and the inhibition was prevented by the Fc $\gamma$ RIIB-blocking antibody (Figure $5 \mathrm{H}$ ). Thus, we found parallel Fc $\gamma$ RIIB-dependent negative effects of HFD-IgG from mice and IgG from humans with T2DM on insulin action in endothelium. These findings, in combination with the comparable detrimental in vivo effects of HFD-IgG from mice and IgG from type 2 diabetics on insulin sensitivity in mice (Figures 3 and 4), suggest that the diabetogenic actions of the IgG-endothelial Fc $\gamma$ RIIB tandem now revealed in obese mice may be operative in T2DM in humans.

IgG hyposialylation and insulin resistance. To determine how IgG is modified in obesity to adversely impact glucose homeostasis via Fc $\gamma$ RIIB in endothelium, we isolated subclasses of IgG from control-fed and HFD-fed mice and tested their effects on insulin activation of eNOS in cultured endothelial cells. Studies were performed with IgG1, IgG2b, and IgG2c, because they bind to Fc $\gamma$ RIIB and IgG3 does not (31). Using CRP as a positive control, we found that IgG1 and IgG2b from HFD-fed mice did not affect insulin activation of eNOS (Figure 6, A and B). In contrast, whereas IgG2c from control-fed mice had no effect, IgG2c from HFD-fed mice fully antagonized insulin stimulation of eNOS (Figure 6C). Recognizing that the relative glycosylation, particularly the sialylation of the Fc glycan on IgG, affects IgG affinity for Fc receptors (32), we then compared the sialylation of IgG2c isolated from control diet- versus HFD-fed mice by Sambucus nigra agglutinin (SNA) lectin blotting (33). The presence of sialic acid on the Fc glycan reduces Fc $\gamma$ RIIB affinity by 10-fold (32). 
A

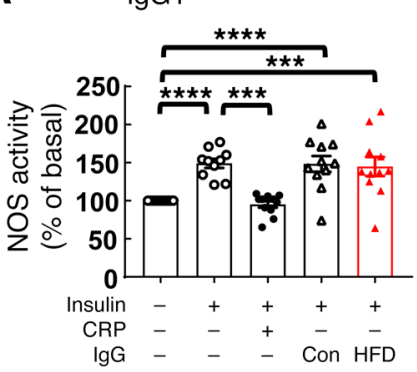

E
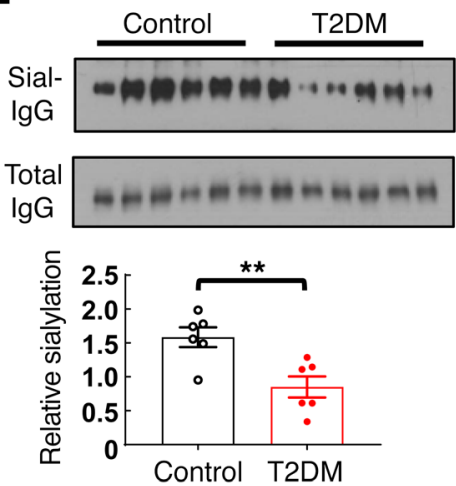

H

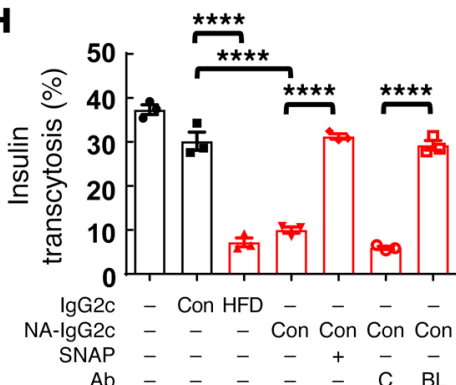

$\mathbf{L}$

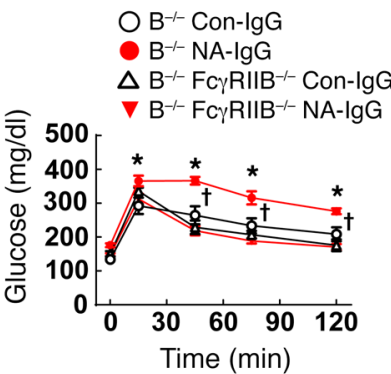

B $\lg G 2 b$

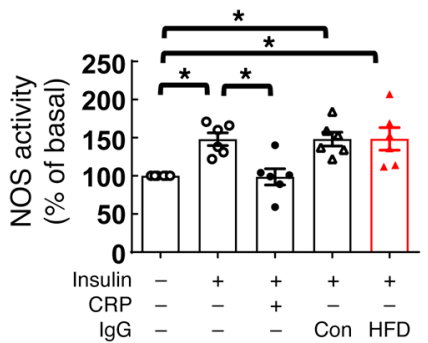

F $\frac{\text { Con }}{-+} \frac{\text { HFD }}{-+}$

Sial-

$\lg \mathrm{G} 2 \mathrm{c}$

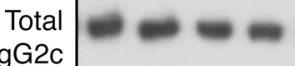

lgG2c

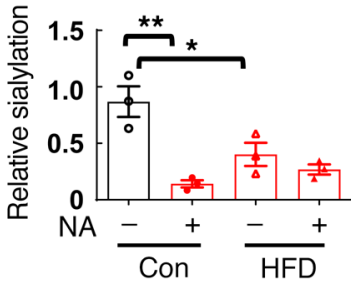

I

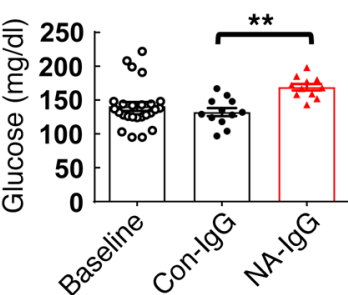

M

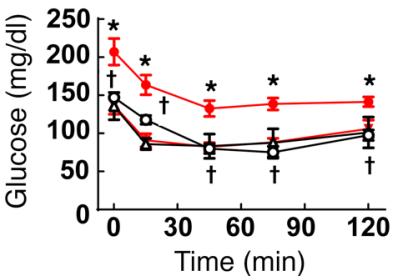

C $\quad \lg G 2 c$

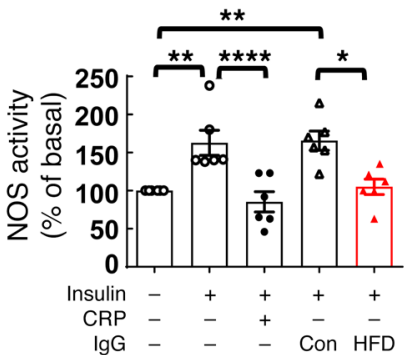

G

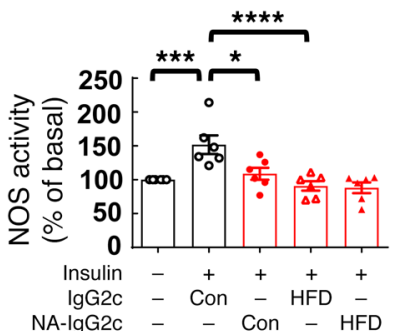

D
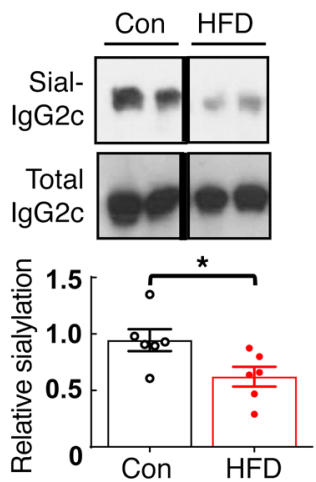

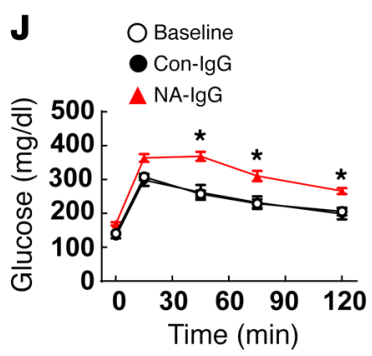

K $\quad$ Con-lgG

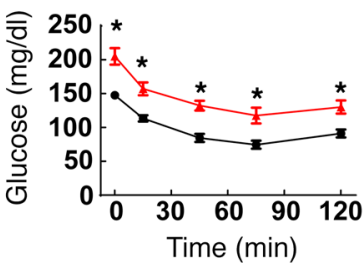

$\mathbf{N}$

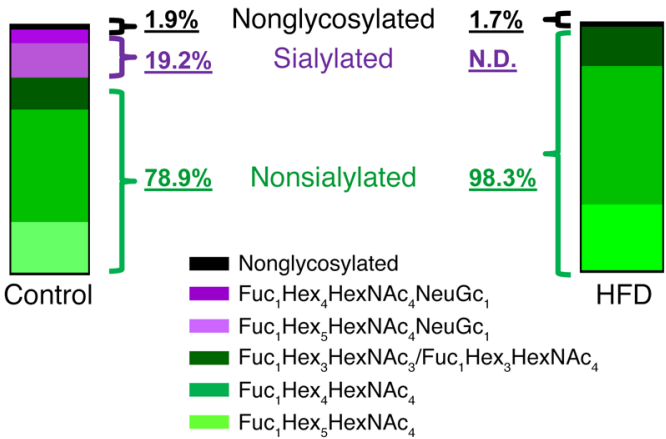

Figure 6. Hyposialylated IgG2c from HFD-fed mice blunts endothelial insulin transcytosis and invokes insulin resistance via Fc $\gamma$ RIIB, and IgG from T2DM subjects is similarly hyposialylated. (A-C) The effects of the IgC subclasses IgG1 (A), IgG2b (B), or IgG2c (C) (10 $\mu$ g/ml) from control diet- or HFD-fed WT mice on eNOS activation by insulin ( $100 \mathrm{nM}$ ) were assessed in cultured endothelial cells. (A-C) $n=6-11$. (D) Sialylation of IgG2c (Sial-IgG2c) from control dietor HFD-fed mice was evaluated by SNA-lectin blotting. $n=6$. (E) Sialylation of IgG isolated from nondiabetic humans and T2DM patients was evaluated by SNA-lectin blotting. $n=6$. (F) lgG2c from control diet- or HFD-fed mice was treated with vehicle (Con) or NA, and sialylation was evaluated by SNA-lectin blotting. $n=3$. (G) Endothelial cells were preincubated with Con-IgG2c or HFD-IgG2c treated with vehicle or NA, and eNOS activation by insulin was assessed. $n=6$. (H) Confluent endothelial cells on Transwells were preincubated with Con-IgG2c or HFD-IgG2c treated with vehicle or NA, and insulin transcytosis was assessed in the absence or presence of the NO donor SNAP (100 nM), control antibody (C, $10 \mu \mathrm{g} / \mathrm{ml})$, or Fc $\gamma \mathrm{RIIB}$-blocking antibody (BL, $10 \mu \mathrm{g} / \mathrm{ml}) . n=7$. (I-K) $\mathrm{B}^{-/-}$mice were fed a HFD for 12 weeks and injected with Con-IgC that was treated ex vivo with vehicle (Con-lgG) or NA (NA-lgG). Fasting plasma glucose was measured before and after 1 week of injections (I), and then GTTs (J) and ITTs (K) were performed. (I-K) $n=7-16 .{ }^{*} P<0.05$, NA versus Con-IgG. (L and $\mathbf{M}$ ) Using the same study design as in I-K, IgG transfer experiments were performed in $\mathrm{B}^{-/-}$and $\mathrm{B}^{-/-}$Fc $\gamma \mathrm{R} / \mathrm{B}^{-/-}$mice administered Con-IgG or NA-IgG. GTTs (L) and

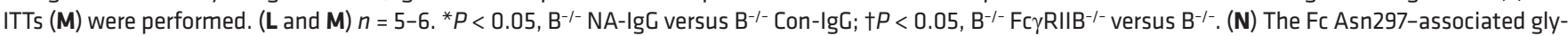
can structure was evaluated by glycoproteomic analysis using pooled mouse Con-IgG2c and HFD-IgG2c. Values represent the mean \pm SEM (A-M). ${ }^{*} P<0.05$, ${ }^{* *} P<0.01,{ }^{* *} P<0.005$, and ${ }^{* * *} P<0.001$, by 1-way ANOVA with Tukey's post-hoc test (A-C and $\left.\mathbf{F}-\mathbf{I}\right)$, Student's $t$ test (D and $\left.\mathbf{E}\right)$, and 2-way ANOVA (J-M). 
A
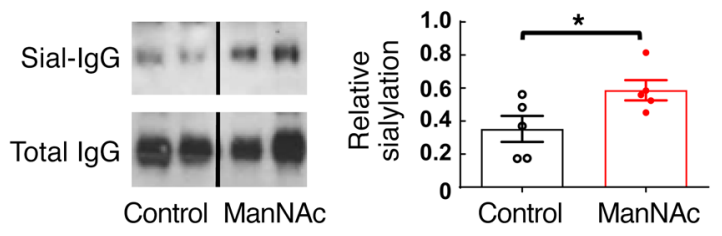

B

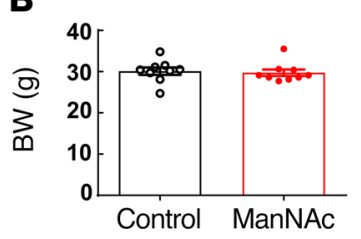

C
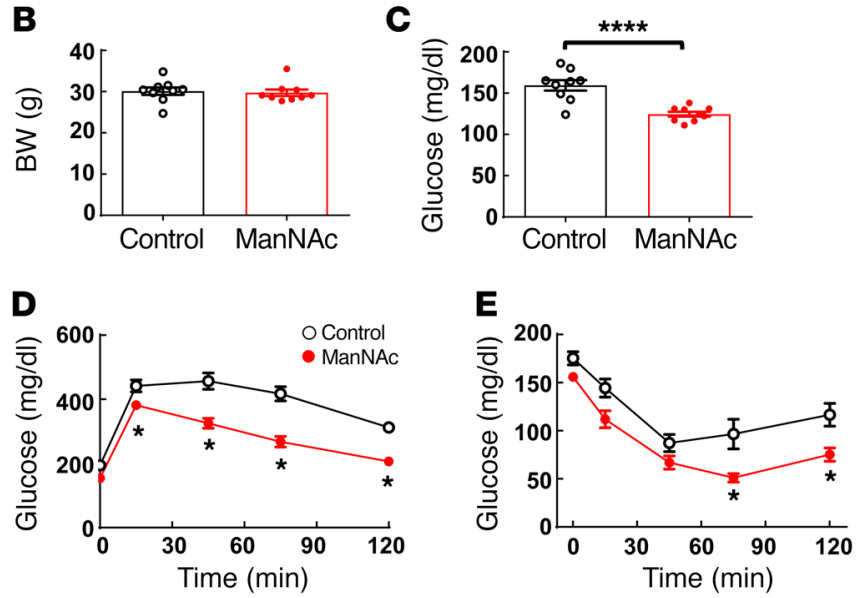

We found that HFD-IgG2c was less sialylated than Con-IgG2c (Figure 6D) and, in contrast, that there was no difference in the sialylation of IgG1 or IgG2b isolated from control diet- or HFDfed mice (Supplemental Figure 11). We then evaluated the time course of temporal changes in IgG2c sialylation versus evidence of glucose intolerance during the development of diet-induced obesity in mice (Supplemental Figure 12). After 2 weeks on a HFD, IgG2c sialylation was unaltered, and the mice had not yet developed glucose intolerance. However, paralleling a decline in IgG2c sialylation after 4 weeks on a HFD, glucose intolerance was evident, and these abnormalities persisted thereafter. Thus, there is a temporal relationship between the development of IgG2c hyposialylation and the development of abnormal glucose homeostasis over the course of HFD-induced obesity in mice. Prompted by the findings regarding IgG2c sialylation in mice, we compared the sialylation levels of IgG isolated from insulin-sensitive human subjects with sialylation levels of IgG from individuals with T2DM (Figure 6E) and discovered a decrease in sialylation of IgG in the T2DM subjects.

Next, we determined whether the degree of sialylation of IgG influences its capacity to alter insulin action in endothelial cells. IgG2c from control diet- and HFD-fed mice was treated with neuraminidase (NA) to invoke desialylation (Figure 6F), and the resulting effects on insulin activation of eNOS in cultured endothelial cells were evaluated. We found that NA-treated, hyposialylated control IgG2c antagonized insulin activation of eNOS to a degree similar to that found with nontreated HFD-IgG2c (Figure $6 \mathrm{G})$. Direct endothelial cell treatment with NA had no impact on insulin activation of eNOS (Supplemental Figure 13A). We also evaluated the effects of IgG hyposialylation on endothelial cell insulin transcytosis (Figure 6H). Transcytosis was comparably inhibited by HFD-IgG and NA-treated Con-IgG, and the inhibition by NA-treated Con-IgG was fully reversed by the NO donor SNAP or by the anti-Fc $\gamma$ RIIB-blocking antibody.
Figure 7. ManNAc treatment protects mice from obesity-induced glucose intolerance and insulin resistance. (A) Male WT mice were fed a HFD and either regular drinking water (control) or ManNAc-supplemented drinking water for 6 weeks. Plasma IgC was isolated, and its sialylation was evaluated by SNA-lectin blotting. Graph depicts the relative sialylation. $n=5$. (B) BW and (C) fasting plasma glucose levels were measured, and (D) a GTT was performed. (E) Mice were continued on the HFD, and an ITT was performed 1 week later. $n=9$. (A-E) Values represent the mean \pm SEM. $(\mathbf{A}-\mathbf{C}){ }^{*} P<0.05$ and ${ }^{* * *} P<0.001$, by Student's $t$ test; ( $\mathbf{D}$ and $\mathbf{E}$ ) ${ }^{*} P<0.05$, ManNAc versus control, by 2-way ANOVA with Tukey's post-hoc test.

We then tested whether the hyposialylation of $\operatorname{IgG}$ invokes insulin resistance in vivo by performing IgG transfer experiments in HFD-fed $\mathrm{B}^{-/-}$mice. The administration of control-treated or NA-treated IgG had no effect on BW (Supplemental Figure 13B). However, whereas mice given control-treated IgG had no change in fasting glucose compared with baseline values, mice given NA-treated IgG developed fasting hyperglycemia (Figure 6I). In parallel, GTTs were shifted upward in mice given NA-treated IgG but not in mice given control-treated IgG, and ITTs were also abnormal in the former group compared with ITTs in the latter (Figure 6, J and K). The administration of NA alone to mice had no effect on GTT or ITT values (Supplemental Figure 13, C and D). Furthermore, whereas NA-treated IgG induced glucose intolerance and insulin resistance in $\mathrm{B}^{-/-}$mice, it had no effect in $\mathrm{B}^{-/-}$ Fc $\gamma \mathrm{RIIB}^{-/-}$mice (Figure 6, L and M).

Having implicated IgG2c hyposialylation in obesity-induced insulin resistance in mice, we used mass spectrometry (MS) to provide specific structural analysis of the glycan attached to $\mathrm{Fc}$ Asn297 in IgG2c from control diet-fed and HFD-fed mice (Figure $6 \mathrm{~N}$ and Supplemental Table 2). We found that, whereas $19.2 \%$ of Fc Asn297-associated glycans in Con-IgG2c were terminally sialylated, HFD-IgG2c Fc Asn297 glycans had no detectable sialylation. However, the abundance of the sugar moieties proximal to the terminal sialic acid was similar in Con-IgG2c and HFD-IgG2c. These collective results reveal that IgG2c is hyposialylated in the setting of diet-induced obesity in mice; that in parallel IgG sialylation is decreased in humans with T2DM; that the hyposialylation causes IgG to antagonize endothelial cell insulin transcytosis via Fc $\gamma$ RIIB and eNOS antagonism; and that the IgG hyposialylation invokes glucose intolerance and insulin resistance in vivo in mice through processes mediated by Fc $\gamma$ RIIB.

Rescue of IgG sialylation and prevention of insulin resistance. Having implicated the hyposialylation of IgG in obesity-induced insulin resistance, we next investigated how the promotion of sialylation potentially impacts the disorder. WT mice placed on a HFD at 5 weeks of age were concurrently given either water alone or water supplemented with the sialic acid precursor $\mathrm{N}$-acetylmannosamine (ManNAc) (34). Six weeks later, we observed an increase in sialylation in IgG isolated from the ManNAc-treated mice (Figure 7A). In the absence of any impact on BW (Figure 7B), ManNAc treatment improved fasting glucose, and GTTs and ITTs revealed that ManNAc afforded protection from obesity-induced glucose intolerance and insulin resistance (Figure 7, C-E). Thus, it may be possible to prevent obesity-related insulin resistance by normalizing the sialylation of IgG. 


\section{Discussion}

T2DM is a common complication of obesity and an important cause of morbidity and mortality worldwide, and its prevalence is increasing. In studies of diet-induced obesity in mice, we reveal that the inhibitory IgG receptor Fc $\gamma$ RIIB in endothelial cells surprisingly plays an important role in obesity-induced insulin resistance. Despite developing an increase in adiposity on a HFD comparable to that seen in control mice, mice globally deficient in Fc $\gamma$ RIIB as well as mice lacking the receptor selectively in endothelium were protected from insulin resistance. This was due to a normalization in skeletal muscle glucose disposal resulting from a preservation of skeletal muscle insulin delivery. We further determined that the operative ligand for endothelial Fc $\gamma$ RIIB invoking obesity-induced insulin resistance was IgG and also showed that Fc receptor activation, and not the previously suggested autoantigen recognition by IgG during obesity, is critical to the pathogenesis of the disorder. Importantly, we have demonstrated for the first time to our knowledge that, in contrast to IgG isolated from metabolically healthy human subjects, IgG from patients with T2DM invokes insulin resistance when given to B cell-deficient mice, and in human endothelial cells, it blocks insulin action. Moreover, both the in vivo detrimental response to human T2DM IgG in mice and its direct inhibitory effect on insulin function in human endothelial cells required Fc $\gamma$ RIIB, providing evidence that these mechanisms may be operative in T2DM in humans. Thus, endothelial Fc $\gamma$ RIIB activation by IgG has been identified as a critical mechanism contributing to the pathogenesis of obesity-induced insulin resistance.

Whereas Fc $\gamma$ RIIB classically influences immune responses in B cells, T cells, DCs, and monocytes/macrophages (35), it is only recently that Fc $\gamma$ RIIB expression and governance of cellular responses has been recognized in endothelium. Fc $\gamma$ RIIB protein was found to be abundant in microvascular endothelium, particularly in skeletal muscle (15), and the receptor protein was also readily detected by FACS in human endothelial cells from various vascular beds (18). Recently, we discovered that the activation of endothelial Fc $\gamma$ RIIB by an artificial elevation of the pentraxin CRP in mice causes insulin resistance (19). However, it was entirely unknown whether Fc $\gamma$ RIIB, CRP, the murine CRP-equivalent acute-phase reactant SAP, the classical receptor ligand $\operatorname{IgG}$, or any related mechanisms participate in obesity-induced insulin resistance. A role for Fc $\gamma$ RIIB in obesity-related disease was first demonstrated when we determined that mice globally deficient in the receptor are protected from obesity-induced hypertension (24). Although further elucidation of the processes whereby the receptor causes blood pressure elevation in obesity is required, the available evidence to date suggests that the hypertension and insulin resistance that complicate obesity may have shared mechanistic origins centered on Fc $\gamma$ RIIB.

Turning to the relevant Fc $\gamma$ RIIB ligand and its cellular source, $\mathrm{B}$ cell involvement in obesity-induced insulin resistance was previously demonstrated in studies showing preservation of normal insulin sensitivity in $\mathrm{B}^{-/-}$mice, despite the development of obesity on a HFD $(27,36)$. The contribution of B cells to diabetes has been attributed to their regulation of $\mathrm{T}$ cell function and macrophage activation and to the effects of autoantibodies targeting selfantigens including islet autoantigens and autoantigens in other cell types $(21,27,36)$. Interestingly, in IgG transfer experiments, Winer and colleagues (27) found that, whereas intact HFD-IgG causes glucose intolerance, $\mathrm{F}\left(\mathrm{ab}^{\prime}\right)_{2}$ fragments have no effect, consistent with our identification of an Fc receptor, specifically Fc $\gamma$ RIIB, as a critical participant in the pathogenesis of obesityinduced insulin resistance. Further demonstrating the requirement for endothelial Fc $\gamma$ RIIB in the adverse effects of HFD-IgG on insulin sensitivity, our search for the basis for altered IgG action excluded changes in IgG abundance. Alternatively, through IgG glycosylation analysis including MS and its manipulation by sialic acid removal with NA, we determined that the glucose intolerance and insulin resistance invoked in mice by HFD-IgG was uniquely related to its hyposialylation in the setting of obesity. We further found that there was relative hyposialylation of IgG from T2DM patients compared with that from healthy controls. The glycan attached to asparagine 297 in the Fc region of IgG influences the binding of IgG to Fc receptors, presumably by changing the conformation of Fc, with the absence of the terminal sialic acid residue increasing receptor affinity (32). IgG glycosylation status has been shown to be of potential importance in rheumatoid arthritis and in the protective effect of i.v. IgG (IVIG) $(33,37)$. We now provide evidence that this form of immune response modulation may participate in an extremely common clinical condition, namely T2DM. Interestingly, our evidence includes demonstrations in mice that the hyposialylation of the relevant IgG subclass IgG2c and glucose intolerance are first observed concomitantly after 4 weeks of HFD feeding. As such, loss-of-function, gain-of-function, and temporal association studies have consistently implicated altered IgG sialylation and Fc $\gamma$ RIIB in obesity-induced insulin resistance.

In addition to revealing the involvement of endothelial Fc $\gamma$ RIIB and its activation by hyposialylated IgG in obesity-induced insulin resistance, we elucidated their pathogenic mechanisms of action. It was previously shown that diet-induced obesity causes a marked attenuation in skeletal muscle insulin delivery (10). However, the basis for the blunting of insulin delivery in obesity was unknown. By cell-specific genetic loss of function, we discovered that endothelial Fc $\gamma$ RIIB is required for the obesity-related impairment in skeletal muscle insulin delivery. Insulin transcytosis studies in cultured endothelial cells further revealed that, as a result of its hyposialylation, HFD-IgG causes an Fc $\gamma$ RIIB-dependent decline in insulin transcytosis that is related to eNOS antagonism. DCE-US experiments in mice further revealed a lack of impact of Fc $\gamma$ RIIB on muscle capillary recruitment or MBF responses to insulin in the setting of obesity, indicating that Fc $\gamma$ RIIB attenuation of endothelial insulin transcytosis most likely explains how the receptor in endothelium impairs skeletal muscle insulin delivery in obese mice. Whereas endothelial Fc $\gamma$ RIIB deletion reversed obesity-related processes in the skeletal muscle, there was no effect on the hepatic insulin resistance that also accompanies obesity. Fc $\gamma$ RIIB modulation of endothelial insulin transcytosis may be irrelevant to hepatic glucose homeostasis, because, in contrast to the skeletal muscle microvasculature, discontinuous endothelium is found in liver sinusoidal vascular beds, and liver sinusoidal endothelium also possess large fenestrations (38).

Having revealed that the terminal hyposialylation of $\operatorname{IgG}$ plays an important role in the insulin resistance associated with obesity, the opportunity arose to test whether the promotion of 
sialylation prevents the insulin resistance. Supplementation of the drinking water with the sialic acid precursor ManNAc effectively normalized IgG sialylation and glucose intolerance and insulin resistance in mice fed a HFD for 6 weeks, without impacting weight gain. Treatment with ManNAc is currently under consideration in individuals with the autosomal recessive neuromuscular disorder hereditary inclusion body myopathy (HIBM) (39), which is caused by mutations in the GNE gene that encodes ManNAc kinase, which catalyzes the first 2 rate-limiting steps in sialic acid synthesis (34). Thus, entirely independent of other interventions targeting the underlying obesity, it may be possible to intervene against T2DM by sialic acid supplementation. Such an approach, as well as strategies affording selective inhibition of endothelial Fc $\gamma$ RIIB, may offer unique opportunities to sever the link between obesity and insulin resistance that now afflict millions of individuals worldwide.

\section{Methods}

Animal model. Experiments were performed in male C57BL/6 WT, $\mathrm{Fc}_{\mathrm{RIIB}}{ }^{-/}, \mathrm{Fc}^{-/-}, \mathrm{B}^{-/-}, \mathrm{SAP}^{-/-}, \mathrm{Fc} \gamma \mathrm{RIIB}{ }^{\mathrm{fl} / \mathrm{fl}}$, and VECad-Cre mice, or in offspring from their mating. $\mathrm{Fc}_{\mathrm{RIIB}} \mathrm{R}^{-/}$mice were obtained from T. Takai (Tohoku University, Sendai, Japan) (15); Fc $\gamma^{-1-}$ mice were obtained from Taconic Biosciences; and $\mathrm{B}^{-/-}$mice were purchased from The Jackson Laboratory. $\mathrm{SAP}^{-/-}$mice were produced as described previously (40). Fc $\gamma$ RIIB $^{\mathrm{fl} / \mathrm{fl}}$ mice were generated and backcrossed with C57BL/6 mice for more than 8 generations as previously reported (19), and Fc $\gamma \mathrm{RIIB}{ }^{\Delta \mathrm{EC}}$ mice were produced by breeding Fc $\gamma \mathrm{RIIB}^{\mathrm{fl} / \mathrm{fl}}$ mice with VECad-Cre mice (19). Beginning at 5 weeks of age, the study mice were fed either a control diet (Research Diets; D12329, with 11\% kcal from fat) or a HFD (Research Diets; D12331, with $58 \%$ kcal from fat) $(41,42)$, and experiments were performed 12-14 weeks later. In a select set of experiments, ManNAc (Sigma-Aldrich) was given in the drinking water (1\%). Concentrations of plasma CRP, SAP, total IgG or IgG subclasses in mice were measured using ELISA reagents from Life Diagnostics, Immunology Consultants Laboratory Inc., ZeptoMetrix Corporation, and Bethyl Laboratories, respectively. Plasma triglycerides were measured by colorimetric enzymatic assay, and plasma free fatty acids were quantified using the VITROS 250 Chemistry System as previously described (43).

Evaluation of body composition, food consumption, and energy expenditure. BW was measured, and fat mass and lean body mass were determined by NMR (Minispec NMR Analyzer; Bruker) (15). Food consumption and energy expenditure were measured during control diet or HFD feeding over a 4-day period, after 10 weeks on the assigned diets. Following acclimatization for 6 days, indirect calorimetry and activity were simultaneously measured in the Mouse Metabolic Phenotyping Core at the University of Texas Southwestern using the Comprehensive Laboratory Animal Monitoring System (Columbus Instruments) (15).

Evaluation of glucose homeostasis and its regulation. GTTs, ITTs, and PTTs were performed as described previously. Following a 4- to 6-hour fast, the mice received an i.p. injection of D-glucose $(1 \mathrm{~g} / \mathrm{kg}$ BW), insulin (1 unit/kg BW), or pyruvate $(2 \mathrm{~g} / \mathrm{kg} \mathrm{BW})$, respectively $(15,44)$. Tail vein blood samples were obtained at the indicated times (Figures 1-4, 6, and 7) for plasma glucose measurement by glucometer (ONE TOUCH Ultra2; Johnson \& Johnson). Fasting plasma insulin concentrations were determined by ELISA (Crystal Chem Inc.; 90080 Ver. 15) (15). Hyperinsulinemic-euglycemic clamps were performed as previously described $(15,45)$. In brief, hyperinsulinemia was initiated with a primed continuous infusion of insulin $(10 \mathrm{mU} / \mathrm{kg} / \mathrm{min})$, while variable infusion of $50 \%$ dextrose allowed for the achievement of a targeted blood glucose level near $125 \mathrm{mg} / \mathrm{dl}$. Constant infusion of ${ }^{3} \mathrm{H}$-glucose for 90 minutes prior to the clamp and throughout the duration of the experiment allowed for calculations of glucose kinetics.

Evaluations of skeletal muscle glucose uptake, insulin signaling, and insulin delivery were performed as previously reported $(15,19)$. To assess skeletal muscle glucose uptake, fasted mice were injected i.p. with 2-deoxy- $\left[{ }^{3} \mathrm{H}\right]$ glucose $\left(\left[{ }^{3} \mathrm{H}\right]-2-D O G ; 2 \mathrm{~g} / \mathrm{kg} ; 10 \mu \mathrm{Ci} / \mathrm{mouse}\right.$; Amersham Radiolabeled Chemicals) mixed with dextrose (20\%), and blood glucose was measured at 0 to 90 minutes. The plasma was deproteinized with ice-cold perchloric acid, the supernatant was neutralized with $\mathrm{KHCO}_{3}$, and radioactivity was determined in a liquid scintillation counter. The glucose-specific activity (degenerations $/ \mathrm{min} / \mu \mathrm{mol}$ ) was calculated by dividing the radioactivity by the glucose concentration, and the AUC was integrated for the duration of the experiment (90 min). Skeletal muscle (soleus and gastrocnemius) was harvested at 90 minutes. To measure the accumulation of $\left[{ }^{3} \mathrm{H}\right]-2-D O G$, muscles were homogenized, the homogenate was precipitated with ice-cold perchloric acid, and following centrifugation, the supernatant was neutralized for 30 minutes with $\mathrm{KHCO}_{3}$, and 2 aliquots were prepared. One aliquot was used to determine total ${ }^{3} \mathrm{H}$ radioactivity, and the other was passed through an anion exchange column (AG 1-X8 Resin; Bio$\mathrm{Rad})$ to remove unbound $\left[{ }^{3} \mathrm{H}\right]-2-\mathrm{DOG}-6$-phosphate. The column was washed with distilled water, and the radioactivity in the eluted volume was measured in a scintillation counter. The difference between total and eluted ${ }^{3} \mathrm{H}$ radioactivity represents accumulated $\left[{ }^{3} \mathrm{H}\right]-2-D O G-6-$ phosphate. The protein pellet was digested with $\mathrm{KOH}$, and the protein concentration was determined by Bradford assay (Bio-Rad). To calculate $\left[{ }^{3} \mathrm{H}\right]-2-D O G$ uptake, the radioactive counts (degenerations/min) were divided by the integrated glucose-specific activity AUC and the sample protein content.

To evaluate skeletal muscle insulin signaling to Akt and insulin delivery, fasted mice received tail vein injections of vehicle (saline) or bovine insulin (1 units/kg BW), the soleus and gastrocnemius were harvested and homogenized in PBS 5 minutes later, and the homogenates were prepared for protein determination by Bradford assay and insulin measurements by ELISA (Crystal Chem Inc.). Phosphorylated Akt (p-Akt) and total Akt were detected by immunoblotting using polyclonal anti-p-Akt (S473; Cell Signaling Technology) and anti-Akt antibodies (Cell Signaling Technology), respectively. See complete unedited blots in the supplemental material. The insulin ELISA used detects both mouse and bovine insulin, with 2.1-fold greater sensitivity for bovine insulin than for mouse insulin.

Evaluation of skeletal muscle microvascular function. DCE-US was performed on the proximal hind limb adductor muscle group (adductor magnus and semimembranosus) at baseline and toward the end of a 2-hour hyperinsulinemic-euglycemic clamp entailing an insulin infusion at $20 \mathrm{mU} / \mathrm{Kg} / \mathrm{min}(46-49)$. Isoflurane anesthesia was given, a right jugular vein catheter was placed for infusions, and the rectal temperature was maintained at $36.5^{\circ} \mathrm{C} \pm 0.5^{\circ} \mathrm{C}$ throughout the procedure using a RightTemp Temperature Monitor and Homeothermic Controller (Kent Scientific Corp.). Blood glucose levels were monitored every 5 minutes by glucometer and main- 
tained at $120 \pm 5 \mathrm{mg} / \mathrm{dl}$. The muscle was imaged in cross-sections in a plane perpendicular to the major muscle fiber direction using a Siemens Sequoia ultrasound system equipped with a high-frequency 15L8 transducer. The transducer was mechanically fixed in position to eliminate motion. A microbubble contrast agent-sensitive imaging mode (cadence pulse sequencing [CPS]) was used with a transmit frequency of 1.0 MHz. Data were recorded and processed offline using custom MATLAB software (MathWorks) (50). The lipid shelled perfluorocarbon-based microbubble contrast agent used was purchased from Advanced Microbubbles Laboratories, and the median bubble diameter ranged from 1.886 to $2.087 \mu \mathrm{m}$. DCE-US imaging was performed for 10 minutes before and after a 1-minute controlled i.v. infusion of contrast media $\left(2.5 \times 10^{7}\right.$ microbubbles in $100 \mu \mathrm{l}$ saline) administered by infusion pump. Regions-of-interest (ROI) were defined, and average time-intensity curves were generated and analyzed to extract measurements of CBV (Ipk), MBF (Tpk and WIR), and both CBV and MBF (AUC; and WOR) (46-48, 51).

Human subjects. Adult human subjects who were metabolically healthy $(n=6)$ or with a previous clinical diagnosis of T2DM $(n=$ 6) were studied. Blood was collected by venipuncture and placed on ice, and plasma was separated immediately and stored at $-80^{\circ} \mathrm{C}$ until IgG isolation was performed. Clinical characteristics of the study subjects are provided in Supplemental Table 1, including their insulin sensitivity and disposition index measured using an insulin-modified frequently sampled i.v. GTT and MINMOD modeling $(52,53)$. At the time of sampling, 3 of the patients with diabetes were not receiving antidiabetic medications, 2 patients were taking metformin and insulin, and 1 patient was taking metformin alone.

IgG purification, SNA lectin blotting, and IgG transfer experiments. Total IgG was purified from mouse or human serum using spin columns (Melon Gel IgG Spin Purification Kit; 45206; Thermo Fisher Scientific). Mouse IgG subclasses IgG1, IgG2b, and IgG2c were separated as previously described (54). Briefly, purified total IgG was applied to a HiTrap Protein A HP column (GE Healthcare) with $100 \mathrm{mM}$ sodium phosphate buffer ( $\mathrm{pH}$ 8.0), and IgG1, IgG2c, and IgG2b were sequentially eluted with $0.1 \mathrm{M}$ citric acid buffer at pH6.0, pH4.6, and pH3.8, respectively. The purity of the obtained IgG subclasses was confirmed by ELISA (Bethyl Laboratories).

Relative IgG sialylation was evaluated by lectin blotting using SNA (Vector Laboratories), which binds specifically to sialic acid attached to terminal galactose in $\alpha-2-6$ linkage. Briefly, IgG was separated by SDS-PAGE and transferred to a PVDF membrane, and the membrane was incubated in Carbo-Free blocking solution for 30 minutes at room temperature, followed by incubation in PBS containing biotinylated SNA $(1 \mu \mathrm{g} / \mathrm{ml})$ for 18 hours at $4^{\circ} \mathrm{C}$. After washing, biotinylated lectin binding was detected by HRP-linked anti-biotin antibody (Cell Signaling Technology) and chemiluminescence methods. In studies evaluating the actions of hyposialylated IgG, the terminal sialic acid was removed from the Fc glycan by treatment with NA. IgG $(500 \mu \mathrm{g})$ was incubated with 100 units of NA in $0.05 \mathrm{M}$ sodium citrate buffer, $\mathrm{pH} 6.0$, at $37^{\circ} \mathrm{C}$ for 20 hours. Effective desialylation was confirmed by SNA-lectin blotting. See complete unedited blots in the supplemental material.

The impact of IgG on glucose homeostasis was determined in IgG transfer experiments. The recipients were male $\mathrm{B}^{-/-}$mice who had received a HFD for the previous 12 weeks. While continuing on a HFD, $\operatorname{IgG}(150 \mu \mathrm{g} /$ dose $)$ was administered i.p. twice a week, and individual glucose homeostasis readouts (GTT or ITT) were performed 1 week apart. In select experiments, the recipient $\mathrm{B}^{-/-}$mice were additionally Fc $_{\text {RIIB }}{ }^{-/}, \mathrm{Fc}_{\mathrm{R}} \mathrm{RIIB}^{\mathrm{f} / \mathrm{fl}}$, or Fc $\gamma \mathrm{RIIB}^{\triangle \mathrm{EC}}$. The IgGs used included total IgG isolated from $\mathrm{WT}$ or $\mathrm{Fc}_{\mathrm{R}} \mathrm{RIB}^{-/-}$male mice given control chow versus a HFD for 12 weeks, total IgG from control chow-fed male mice treated ex vivo with buffer versus NA prior to administration, and total IgG isolated from insulin sensitive versus human subjects with T2DM. In the latter experiment, each individual human IgG sample was administered to 3 to 5 mice, and the values obtained were averaged to yield a single value per IgG sample. In a control experiment related to the IgG transfer studies with NA-treated IgG, possible effects on glucose homeostasis of NA alone, administered at a dose equal to that received with NA-treated IgG, were evaluated.

Glycoproteomic analysis. Mouse IgG2c samples (0.65-0.70 mg/ $\mathrm{ml}$, control and HFD) were cleaved into Fc and Fab portions by immobilized papain (Pierce Fab Preparation Kit; Thermo Fisher Scientific) according to the manufacturer's protocol. The IgG2c Fc domain was separated by a protein A-plus spin column, and the eluate was dried by vacuum centrifugation and stored at $-80^{\circ} \mathrm{C}$ until further analysis. The dried samples were dissolved in $100 \mu \mathrm{l}$ of nanopure water, mixed with $2 \times$ Laemmli sample buffer (Bio-Rad), and subjected to SDS-PAGE, and in-gel digestion of IgG by sequencing grade trypsin (Promega) was performed as previously described (55). The samples underwent nano-liquid chromatography tandem MS (LC-MS/MS) analysis using Orbitrap Fusion (Thermo Fisher Scientific) equipped with a Nanospray Flex source with CID, HCD, and ETD options and a Dionex UltiMate 3000 Autosampler LC system (Thermo Fisher Scientific). LC separation was performed on a nanoViper-C18 column using a water/acetonitrile gradient with formic acid. The MS precursor scan was performed using an Orbitrap detector at 120,000 Orbitrap resolution in positive mode. MS/MS fragment ions were analyzed using an Orbitrap detector at 30,000 Orbitrap resolution. The resulting data were initially used for protein identification, which was achieved by searching a protein database from Mus musculus (mouse, downloaded from UniProt, http://www.uniprot.org/) using the Sequest HT Search Wizard in the software Proteome Discoverer 1.4 (Thermo Fisher Scientific). Trypsin was selected as the digestion enzyme, specific cleavage sites (the carboxyl side of lysine and arginine) were enabled, and up to 2 missed cleavages were allowed. Differential search parameters were allowed for the protein identity check, with carboxyamidomethylation of cysteine as a fixed modification and oxidation of methionine as a variable modification. The data were subsequently manually analyzed for glycopeptides using Byonic (Protein Metrics Inc.) and Xcalibur (Thermo Fisher Scientific) software. The MS/MS spectra of glycopeptides were screened and evaluated for oxonium ions, monosaccharide and oligosaccharide neutral loss patterns, and their peptide backbone fragmentations to determine the existence of glycans in these glycopeptides and the sequence of their peptide backbones.

Cell culture experiments. Primary BAECs were obtained as previously described (28), primary HAECs were purchased from Lonza, and cells were used within 5 to 7 passages. To evaluate the requirement for Fc $\gamma$ RIIB in actions of IgG on BAECs, cells were transfected with siRNA using Lipofectamine 2000 (Invitrogen, Thermo Fisher Scientific). Double-stranded (ds) RNA with the sequence 5'-GAAACCAGCCUCUGAAUAAUU- $3^{\prime}$ was designed to target the ORF of bovine 
Fc $\gamma$ RIIB (GenBank accession number NM_174539), and nontargeting siRNA was used as a negative control (ON-TARGETplus Nontargeting siRNA; D-001810-02-20; Dharmacon). Forty-eight hours after transfection, the knockdown of Fc $\gamma$ RIIB was evaluated by immunoblotting using eNOS abundance to assess protein loading. See complete unedited blots in the supplemental material.

In studies of eNOS activation, the conversion of $\left[{ }^{14} \mathrm{C}\right]-\mathrm{L}$-arginine to $\left[{ }^{14} \mathrm{C}\right]$-L-citrulline by intact cells was measured for 15 minutes in the absence (basal) or presence of insulin $(100 \mu \mathrm{g} / \mathrm{ml})$ (28). Additional treatments included CRP ( $25 \mu \mathrm{g} / \mathrm{ml}$; Sigma-Aldrich), mouse total IgG, IgG1, IgG2b, or IgG2c, or human total IgG $(10 \mu \mathrm{g} / \mathrm{ml})$ present during a 30-minute preincubation and also during the 15-minute incubation for quantification of NOS activity. In select studies, mouse IgG was treated with vehicle or NA, as described above, before addition to the cells, and the impact of an equal concentration of NA alone was also determined as a control.

Endothelial cell insulin transcytosis was studied in HAECs as previously described (56). Cells were seeded onto Transwell inserts (6.5-mm diameter, $3-\mu \mathrm{m}$ pore size, polycarbonate membrane inserts; Sigma-Aldrich) treated with collagen I (BD Bioscience), and TEER was monitored 4-5 days later using an epithelial voltohmmeter (EVOM) (World Precision Instruments) to confirm the establishment of a confluent monolayer. Vehicle, CRP $(25 \mu \mathrm{g} / \mathrm{ml})$, mouse IgG $(10 \mu \mathrm{g} /$ $\mathrm{ml}$ ), L-NAME (2 mM; Sigma-Aldrich), or CRP or mouse IgG plus the NO donor S-nitroso- $N$-acetylpenicillamine (100 nM; SNAP; SigmaAldrich) was then added together with FITC-insulin (50 nM; SigmaAldrich) into the upper chamber, and the cells were incubated for 2 hours at $37^{\circ} \mathrm{C}$. In a separate set of experiments, vehicle, CRP, or mouse IgG in the presence of control IgG (10 $\mu \mathrm{g} / \mathrm{ml}$; mouse IgG1; Abcam) or anti-Fc $\gamma$ RIIB-blocking antibody $(10 \mu \mathrm{g} / \mathrm{ml}$; AT10; Abcam) was placed into the upper chamber along with FITC-insulin. At the end of the incubation, the FITC-insulin in the lower chamber was quantified using a fluorimeter (POLARstar Omega; BMG LABTECH), and the percentage of insulin initially placed into the upper chamber that was transported to the bottom chamber was calculated. FITC-dextran (molecular weight 4,000; Sigma-Aldrich) was used to assess paracellular transport, and only $3.8 \%$ of FITC-dextran $(n=4)$ added to the upper chamber was detected in the lower chamber after 2 hours, indicating negligible paracellular molecule transport.
Statistics. Comparisons between 2 groups were done using a 2-tailed Student's $t$ test. Differences between multiple groups were evaluated by 1- or 2-way ANOVA with Tukey's or Sidak's post-hoc test. Values shown represent the mean \pm SEM. A $P$ value of less than 0.05 was considered statistically significant.

Study approval. The care and use of all study animals were approved by the IACUC of the University of Texas Southwestern Medical Center. The human studies were approved by the IRB of the University of Texas Southwestern Medical Center, and all subjects provided written informed consent prior to their participation in the study.

\section{Author contributions}

KT, AS, JP, KLC, ISY, DG, MA, QC, and AJS conducted the experiments and analyzed the data. KLC, AJS, and MB generated the mouse strains. IL recruited the human subjects, collected the human samples, and contributed to the experimental design. WV, RFM, PA, IL, WLH, JJK, SRS, and KH contributed to methods development, experimental design, and data analysis. PWS and $\mathrm{CM}$ designed the experiments, interpreted the data, and wrote the manuscript. All authors discussed the results and commented on the manuscript.

\section{Acknowledgments}

This work was supported by American Diabetes Association grant 1-10-BS-124 (to CM); American Heart Association grant 13GRNT16080003 (to CM); The Hartwell Foundation (to PWS); the Cancer Prevention Research Institute of Texas (CPRIT) (RR150010, to RFM); and NIH grants R01DK110127 (to CM), R01HL115122 (to PWS), T32 HL098040 (to AS), R01DK099092 (to AJS), K23 RR024470 (to IL), 1S10 OD018530 and P41GM10349010 (to PA), R01DK108833 (to WLH), R01GM090271 (to JJK), and K25EB017222 and R21CA212851 (to KH).

Address correspondence to: Chieko Mineo or Philip W. Shaul, Department of Pediatrics, University of Texas Southwestern Medical Center, 5323 Harry Hines Blvd, Dallas, Texas 75390, USA. Phone: 214.648.8426; Email: Chieko.Mineo@utsouthwestern.edu (C. Mineo). Phone: 214.648.2015; Email: Philip.Shaul@ utsouthwestern.edu (P.W. Shaul).
1. Seuring T, Archangelidi O, Suhrcke M. The Economic Costs of Type 2 Diabetes: A Global Systematic Review. Pharmacoeconomics. 2015;33(8):811-831.

2. Global Burden of Metabolic Risk Factors for Chronic Diseases Collaboration. Cardiovascular disease, chronic kidney disease, and diabetes mortality burden of cardiometabolic risk factors from 1980 to 2010: a comparative risk assessment. Lancet Diabetes Endocrinol.2014;2(8):634-647.

3. NCD Risk Factor Collaboration (NCD-RisC). Worldwide trends in diabetes since 1980: a pooled analysis of 751 population-based studies with 4.4 million participants. Lancet. 2016;387(10027):1513-1530.

4. Després JP, Lemieux I. Abdominal obesity and metabolic syndrome. Nature. 2006;444(7121):881-887.

5. Danaei G, et al. National, regional, and global trends in fasting plasma glucose and diabetes prevalence since 1980: systematic analysis of health examination surveys and epidemiological studies with 370 country-years and 2.7 million participants. Lancet. 2011;378(9785):31-40.

6. Portero McLellan KC, Wyne K, Villagomez ET, Hsueh WA. Therapeutic interventions to reduce the risk of progression from prediabetes to type 2 diabetes mellitus. Ther Clin Risk Manag. 2014;10:173-188.

7. Eckel RH, et al. Obesity and type 2 diabetes: what can be unified and what needs to be individualized? Diabetes Care. 2011;34(6):1424-1430.

8. DeFronzo RA, Ferrannini E, Hendler R, Felig P, Wahren J. Regulation of splanchnic and peripheral glucose uptake by insulin and hyperglycemia in man. Diabetes. 1983;32(1):35-45.

9. Dawson D, et al. Vascular recruitment in skeletal muscle during exercise and hyperinsulinemia assessed by contrast ultrasound. Am J Physiol Endocrinol Metab. 2002;282(3):E714-E720.

10. Kubota T, et al. Impaired insulin signaling in endothelial cells reduces insulin-induced glucose uptake by skeletal muscle. Cell Metab. 2011;13(3):294-307.

11. Manrique C, Sowers JR. Insulin resistance and skeletal muscle vasculature: significance, assessment and therapeutic modulators. Cardiorenal Med. 2014;4(3-4):244-256.

12. Festa A, D'Agostino R, Howard G, Mykkänen L, Tracy RP, Haffner SM. Chronic subclinical inflammation as part of the insulin resistance syndrome: the Insulin Resistance Atherosclerosis Study (IRAS). Circulation. 2000;102(1):42-47.

13. Haffner SM. The metabolic syndrome: inflammation, diabetes mellitus, and cardiovascular disease. Am J Cardiol. 2006;97(2A):3A-11A.

14. Pradhan AD, Manson JE, Rifai N, Buring JE, 
Ridker PM. C-reactive protein, interleukin 6, and risk of developing type 2 diabetes mellitus. JAMA. 2001;286(3):327-334.

15. Tanigaki K, et al. C-reactive protein causes insulin resistance in mice through Fcgamma receptor IIB-mediated inhibition of skeletal muscle glucose delivery. Diabetes. 2013;62(3):721-731.

16. Bruhns $P$, et al. Specificity and affinity of human Fcgamma receptors and their polymorphic variants for human IgG subclasses. Blood. 2009;113(16):3716-3725.

17. Lu J, Marnell LL, Marjon KD, Mold C, Du Clos TW, Sun PD. Structural recognition and functional activation of FcgammaR by innate pentraxins. Nature. 2008;456(7224):989-992.

18. Tanigaki K, Sundgren N, Khera A, Vongpatana$\sin$ W, Mineo C, Shaul PW. Fc $\gamma$ receptors and ligands and cardiovascular disease. Circ Res. 2015;116(2):368-384.

19. Tanigaki K, et al. Endothelial Fc $\gamma$ Receptor IIB Activation Blunts Insulin Delivery to Skeletal Muscle to Cause Insulin Resistance in Mice. Diabetes. 2016;65(7):1996-2005.

20. Nimmerjahn F, Ravetch JV. Fc-receptors as regulators of immunity. Adv Immunol. 2007;96:179-204.

21. Tsai S, Clemente-Casares X, Revelo XS, Winer S, Winer DA. Are obesity-related insulin resistance and type 2 diabetes autoimmune diseases? Diabetes. 2015;64(6):1886-1897.

22. Alva JA, et al. VE-Cadherin-Cre-recombinase transgenic mouse: a tool for lineage analysis and gene deletion in endothelial cells. Dev Dyn. 2006;235(3):759-767.

23. Teupser D, Weber O, Rao TN, Sass K, Thiery J, Fehling HJ. No reduction of atherosclerosis in C-reactive protein (CRP)-deficient mice. J Biol Chem. 2011;286(8):6272-6279.

24. Sundgren NC, et al. IgG receptor Fc $\gamma$ RIIB plays a key role in obesity-induced hypertension. Hypertension. 2015;65(2):456-462.

25. Mold C, Baca R, Du Clos TW. Serum amyloid $\mathrm{P}$ component and C-reactive protein opsonize apoptotic cells for phagocytosis through Fcgamma receptors. J Autoimmun. 2002;19(3):147-154.

26. Pepys MB, Baltz M, Gomer K, Davies AJ, Doenhoff M. Serum amyloid P-component is an acute-phase reactant in the mouse. Nature. 1979;278(5701):259-261.

27. Winer DA, et al. B cells promote insulin resistance through modulation of $\mathrm{T}$ cells and production of pathogenic IgG antibodies. Nat Med. 2011;17(5):610-617.

28. Tanigaki K, et al. C-reactive protein inhibits insu- lin activation of endothelial nitric oxide synthase via the immunoreceptor tyrosine-based inhibition motif of FcgammaRIIB and SHIP-1. Circ Res. 2009;104(11):1275-1282.

29. Wang H, Wang AX, Aylor K, Barrett EJ. Nitric oxide directly promotes vascular endothelial insulin transport. Diabetes. 2013;62(12):4030-4042.

30. Lee WL, Klip A. Endothelial Transcytosis of Insulin: Does It Contribute to Insulin Resistance? Physiology (Bethesda). 2016;31(5):336-345.

31. Bruhns P. Properties of mouse and human IgG receptors and their contribution to disease models. Blood. 2012;119(24):5640-5649.

32. Anthony RM, Wermeling F, Ravetch JV. Novel roles for the IgG Fc glycan. Ann N Y Acad Sci. 2012;1253:170-180.

33. Kaneko Y, Nimmerjahn F, Ravetch JV. Anti-inflammatory activity of immunoglobulin $\mathrm{G}$ resulting from $\mathrm{Fc}$ sialylation. Science. 2006;313(5787):670-673.

34. Galeano B, et al. Mutation in the key enzyme of sialic acid biosynthesis causes severe glomerular proteinuria and is rescued by N-acetylmannosamine. J Clin Invest. 2007;117(6):1585-1594.

35. Ravetch JV, Lanier LL. Immune inhibitory receptors. Science. 2000;290(5489):84-89.

36. DeFuria J, et al. B cells promote inflammation in obesity and type 2 diabetes through regulation of T-cell function and an inflammatory cytokine profile. Proc Natl Acad Sci U S A. 2013;110(13):5133-5138.

37. Rademacher TW, Jones RH, Williams PJ. Significance and molecular basis for IgG glycosylation changes in rheumatoid arthritis. Adv Exp Med Biol. 1995;376:193-204.

38. Aird WC. Phenotypic heterogeneity of the endothelium: I. Structure, function, and mechanisms. Circ Res. 2007;100(2):158-173.

39. Nishino I, Carrillo-Carrasco N, Argov Z. GNE myopathy: current update and future therapy. J Neurol Neurosurg Psychiatr. 2015;86(4):385-392.

40. Botto M, et al. Amyloid deposition is delayed in mice with targeted deletion of the serum amyloid P component gene. Nat Med.1997;3(8):855-859.

41. Parekh PI, Petro AE, Tiller JM, Feinglos MN, Surwit RS. Reversal of diet-induced obesity and diabetes in C57BL/6 J mice. Metab Clin Exp. 1998;47(9):1089-1096.

42. Surwit RS, et al. Differential effects of fat and sucrose on the development of obesity and diabetes in C57BL/6J and A/J mice. Metab Clin Exp. 1995;44(5):645-651.

43. Chambliss KL, et al. Nonnuclear Estrogen Receptor
Activation Improves Hepatic Steatosis in Female Mice. Endocrinology. 2016;157(10):3731-3741.

44. Barrera J, et al. Bazedoxifene and conjugated estrogen prevent diet-induced obesity, hepatic steatosis, and type 2 diabetes in mice without impacting the reproductive tract. Am JPhysiol Endocrinol Metab. 2014;307(3):E345-E354.

45. Holland WL, et al. Receptor-mediated activation of ceramidase activity initiates the pleiotropic actions of adiponectin. Nat Med. 2011;17(1):55-63.

46. Hoyt K, Umphrey H, Lockhart M, Robbin M, Forero-Torres A. Ultrasound imaging of breast tumor perfusion and neovascular morphology. Ultrasound Med Biol. 2015;41(9):2292-2302.

47. Hoyt K, Sorace A, Saini R. Quantitative mapping of tumor vascularity using volumetric contrast-enhanced ultrasound. Invest Radiol. 2012;47(3):167-174.

48. Saini R, Hoyt K. Recent developments in dynamic contrast-enhanced ultrasound imaging of tumor angiogenesis. Imaging Med. 2014;6(1):41-52.

49. Lucidarme O, et al. Angiogenesis: noninvasive quantitative assessment with contrast-enhanced functional US in murine model. Radiology. 2006;239(3):730-739.

50. Ta CN, Kono Y, Barback CV, Mattrey RF, Kummel AC. Automating tumor classification with pixel-by-pixel contrast-enhanced ultrasound perfusion kinetics. J Vac Sci Technol B Nanotechnol Microelectron. 2012;30(2):2C103.

51. Wiprud T. Daniel LeRay Borden, M.D. (1887-1969). Med Ann Dist Columbia. 1970;39(3):183-184.

52. Soonthornpun S, Setasuban W, Thamprasit A, Chayanunnukul W, Rattarasarn C, Geater A. Novel insulin sensitivity index derived from oral glucose tolerance test. JClin Endocrinol Metab. 2003;88(3):1019-1023.

53. Bergman RN, Ader M, Huecking K, Van Citters G. Accurate assessment of beta-cell function the hyperbolic correction. Diabetes. 2002; 51 Suppl 1:S212-S220.

54. Ey PL, Prowse SJ, Jenkin CR. Isolation of pure IgG1, IgG2a and IgG2b immunoglobulins from mouse serum using protein A-sepharose. Immunochemistry. 1978;15(7):429-436.

55. Shevchenko A, Tomas H, Havlis J, Olsen JV, Mann M. In-gel digestion for mass spectrometric characterization of proteins and proteomes. Nat Protoc. 2006;1(6):2856-2860.

56. Wang H, Liu Z, Li G, Barrett EJ. The vascular endothelial cell mediates insulin transport into skeletal muscle. Am J Physiol Endocrinol Metab. 2006;291(2):E323-E332. 